\title{
Complex wing spar design in carbon fiber reinforced composite for a light aerobatic aircraft
}

\author{
Clément Fleuret ${ }^{1}$, Anne-Sophie Andreani ${ }^{1, a}$, Éric Lainé ${ }^{2}$, Jean-Claude Grandidier ${ }^{2}$, \\ Sylvain L'HÉRITIER ${ }^{1}$ And AnNe-Laure Gorge ${ }^{2}$ \\ 1 RESCOLL Rochefort, Rue Maurice Mallet, 17303 Rochefort, France \\ 2 Institut Pprime - CNRS-ENSMA-Université de Poitiers-UPR 3346, Département Physique et Mécanique des Matériaux, \\ France
}

Received 16 October 2015, Accepted 9 May 2016

\begin{abstract}
The challenge concerns the realization of the lightest composite wing for E-FAN prototype 1.0 aircraft. This wing must be dismantled and must support critical loads for aerobatics. The bonding conception between the composites parts must transfer the high loads. This article presents a methodology to design a multi-materials structure with a complex geometry of varying thickness. So, the mechanical behavior must be known for the structure, as well as their weaknesses which can involve the rupture. For that, numerical simulations are elaborated in taken into account the constraints inherent in the manufacturing processes and DGAC's requirements (Direction Générale de l'Aviation Civile, French Authorities for Civil Aviation). The predictive character of these models is realized by numerical and experimental results correlations in order to optimize the numerical model accuracy. Indeed, the complete spar's sizing is validated by static rupture tests. This last point requires the building of a special testing equipment which is able to generate a load compared to the one applied in flight. Moreover, the testing metrology is used to quantify the accuracy level of models. Wing spar, central spar and central/wing bonding are qualified by DGAC for flight.
\end{abstract}

Key words: Composite / wing / structures testing / numerical simulations / acoustic emission

\section{Introduction}

The light aviation is divided into different categories such as ballooning, ultra-light, aerobatics aircraft..., each one is governed by a dedicated standard.

In according to their category, the planes have got the same wing architecture since the beginning of aviation (Fig. 1a). It consists of a main spar which supports bending forces generated by the wing lift; a rear spar which withstands the control surfaces; the ribs which reduce the buckling of the skin and keep the aerodynamic shape; and the skin which transfers the stresses to the spar. Stringers can be added to the ribs into the internal architecture in order to save the profile shape during the wing deflection. For example, Louis Blériot had already used this kind of building for his Blériot XIV which was manufactured with wood and cotton. Then, this architecture was moved with metallic and more recently, composite materials. However, the wooden wings are still very current in light aviation.

\footnotetext{
${ }^{a}$ Corresponding author: as.andreani@rescoll.fr
}

Aircrafts with dismountable wings are an exception when they are manufactured for aerobatics. The bond between the wing and the fuselage is often at the wing root. This connection between each wing is ensured by two pins in the fuselage as shown in Figure 1. The pins located on the axis (Fig. 1b) are usually chosen because the loadings transfer are lower through the pins.

Today, innovation extends beyond the constitutive material in general aviation. New propulsion modes are under development including electric propulsion and they are driven by European vision Flightpath 2050. In this case, batteries have to replace the fuel tanks but the stored energy density in batteries is lower than the one in fuel tank. In order to increase the proportion of storage, the weight reduction of the structures becomes an important challenge. E-Fan prototype 1.0. is an example of aircraft with a new propulsion. This aircraft is fully composite to reduce the structure weight and the engines solicitation. The designers wanted E-Fan prototype 1.0. to be defined as an aerobatic training aircraft with one hour of autonomy in flight. Moreover, its low noise nuisance allows to fly close to aerodromes. The wings are removable to facilitate transport and storage of the aircraft. The 


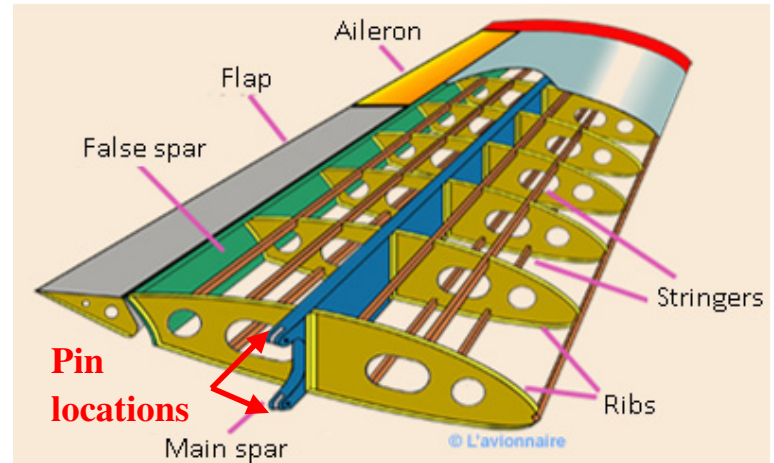

(a)

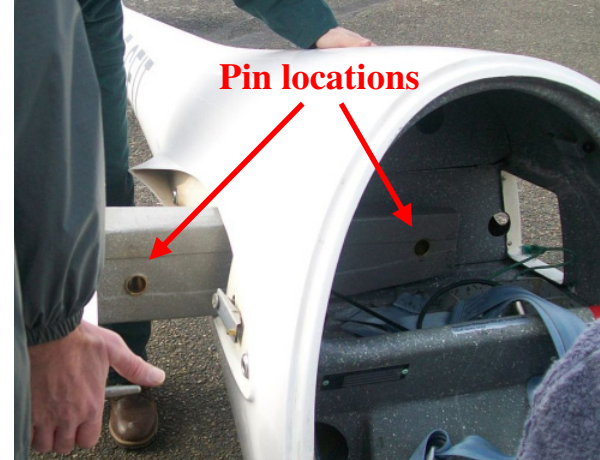

(b)

Fig. 1. (a) Illustration of classical architecture with constitutive parts and (b) bond between wings spars into the fuselage by pins.

batteries are located into the wing in order to be easily interchangeable. The main issue is the little available space for the wing-fuselage connection because of the batteries storage. The loadings flow through the wing and the connection is too high for this kind of aircraft; the skin cannot be used to support partially the loads because of the openings for the batteries changes.

E-FAN prototype 1.0. wing design is in according to the designer requirements and the following aeronautical standards: CS 23 (Certification Specification) with AMC 572 and AMC 619 (Acceptable Means of Compliance) of CS-VLA (Certification Specification - Very Light Aeroplanes). These aeronautical standards impose that all bending loads are supported by the spar alone, so the complete spar is the main element to size. Moreover, the spar sizing must not be planned to observe damage below the limit load, value imposed by these aeronautical standards.

In the context of this industrial project, it is not financially possible to build several prototypes in order to validate the wing concept including connection. But, the license to fly from DGAC (Direction Générale de l'Aviation Civile, French Authorities for Civil Aviation) cannot be obtained without testing a prototype. So, a single set of wings and a single spar can be manufactured in order to validate the mechanical behavior for the wing qualification. The main technical challenge is the complete spar realization of E-FAN prototype 1.0 and we have any knowledge on the behavior of this new architecture and its rupture mode. The numerical simulations only allow to predict the particular architecture response. However, the virtual model has to be efficient to grasp the kinematic and to assess the stresses. The difficulties are not focused on the material behavior, but they are about the pertinent numerical model building of a structure with multi materials. In order to elaborate this accurate model, a confrontation with the experiments can only validate the numerical choices.

The semi structures are usually used for the conception studies like composite plates with hole [1], T semi structures [2], and assembling parts [3]. They are built in order to validate the models by testing. Today, the complex behavior models exist fully integrating anisotropy, damage, viscosity, stochastic phenomena $[1,4-8]$. Some good results are not systematically obtained by using these models for a multi-materials structure with a complex geometry of varying thickness. Indeed, the overlaps of all approximations make difficult the model accuracy: the behavior schematization, the architecture representation, the limited mastery of testing. A perfect correlation has to be reached in a complex case, by a progressive approach to identify and understand the misstatements. For E-FAN spar, no basic knowledge is available, so we have to simultaneously study the model building and the mastery of tests.

In this paper, a methodology is presented to improve the model building and the testing simultaneously in order to design a multi-materials structure with a complex geometry. It can be transferred to any one designed object in mechanical industry. Indeed, the mechanical behavior of this complex structure is difficult to know, as well as their weaknesses which can start the rupture process. For that, numerical simulations are elaborated in taken into account the constraints inherent in the manufacturing processes and DGAC's requirements (Direction Générale de l'Aviation Civile, French Authorities for Civil Aviation). The predictive character of these models is realized by numerical and experimental results correlations on small representative structure. This numerical tool must allow to optimize the model accuracy and the mechanical behavior comprehension of structure failure.

This article is divided into 4 chapters. After explaining the context in Section 1, materials and wing architecture are presented in Section 2 and the numerical model of the complete wing is detailed. To ensure the predictive character of the numerical model, Section 3 describes the experimental validation step by testing the representative semi structures. Specifically, these representative elements has the same manufacturing method as the spar. The experimental results are compared with the ones from numerical model, by using the same parameters as the ones used for the wing sizing. So, the predictive character is improved before testing complete spars. Section 4 presents the qualification test of the complete 
Table 1. Mechanical properties obtained by sample tests.

\begin{tabular}{cccc}
\hline Mean values & Experimental & Standard deviation & Reference \\
\hline Longitudinal tensile elastic modulus & $129 \mathrm{GPa}$ & $1.89 \%$ & $135 \mathrm{GPa}$ \\
Poisson Ratio & 0.25 & $2.32 \%$ & \\
Longitudinal ultimate tensile strength & $1777 \mathrm{MPa}$ & & $1900 \mathrm{MPa}$ \\
Transversal tensile elastic modulus & $7152 \mathrm{MPa}$ & $2.55 \%$ & $7372 \mathrm{MPa}$ \\
Transversal ultimate tensile strength & $40.0 \mathrm{MPa}$ & $5.74 \%$ & $59 \mathrm{MPa}$ \\
Longitudinal compressive elastic modulus & $116 \mathrm{GPa}$ & $4.83 \%$ & $120 \mathrm{GPa}$ \\
Longitudinal ultimate compressive strength & - & - & \\
Shear modulus & $7301 \mathrm{MPa}$ & $0.40 \%$ & \\
Ultimate shear strength & $163.6 \mathrm{MPa}$ & $4.34 \%$ & \\
\hline
\end{tabular}

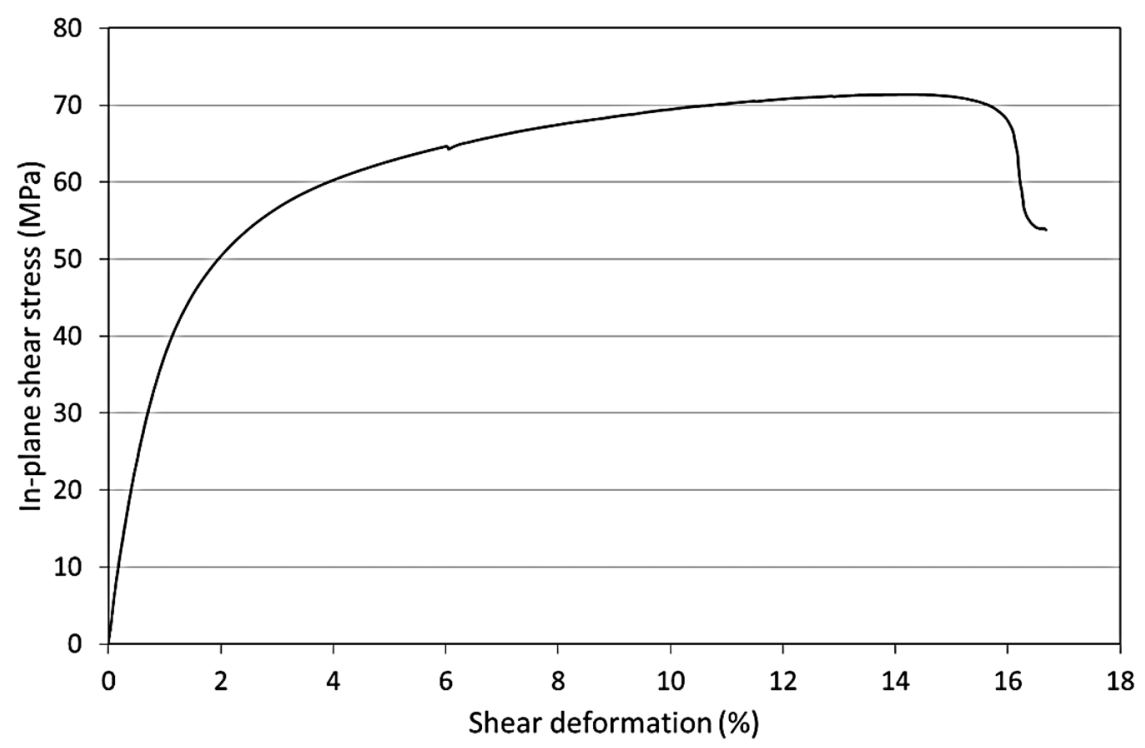

Fig. 2. Stress-deformation curve of anisotropic laminate ( $45^{\circ}$ angle ply) by tensile test.

spar required by DGAC. The numerical model is assessed by comparison between experimental results from the test and the analysis of the rupture scenario.

\section{Dismountable wing design}

\subsection{Materials characterization}

It is firstly necessary to know the material characteristics in order to develop a predictive numerical tool in the design of a complex structure.

Thus, samples are manufactured in carbon-epoxy composite and they are representative of the material for the whole structure. The raw materials are distributed by Structil: prepregs $\left(300\right.$ g. $\left.\mathrm{m}^{-2}\right)$ with TR50 carbon fibers and with an R367-2 epoxyde matrix. In according to the test standards, the composite materials are tested by longitudinal tensile, transverse tensile, shear and longitudinal compression, each one is monotonous. During the test, the stains are measured by strain gauges.

Table 1 summarizes the mechanical characteristics which have been identified. AMC 572 - CS VLA requires a maximum stresses which are $400 \mathrm{MPa}$ for parts in carbonepoxy composite at the limit load $[9,10]$. No detail is provided regarding the ply orientation and the ply stacking.
Then, these maximum stresses are imposed in the fiber direction; the real strengths are used in other directions with a safety factor of 1.5. The reference data values (Table 1) are from the literature, excepted for the longitudinal stress rupture which comes from a manufacturer's documentation [11].

The primary structures should support the bending load. Fibers which are subjected to high compression stresses, are in position to generate a high stiffness. The behavior in fiber direction is elastic linear. The nonlinear ply behavior relies on experimental results from tensile test of laminate with $45^{\circ}$ angle ply (Fig. 2) in order to better know the kinematic. The testing speed is similar to the one for the complete structure test which is carried on structure test bench. Moreover, this nonlinear behavior is represented by an elastoplastic anisotropic model developed by Gentilleau [8]. This model allows to better report of the elastic linear behavior under loads following fiber direction or loads in perpendicular fiber direction and, the nonlinear behavior under shearing loads.

Furthermore, the load is applied by linearly increasing until failure without discharge in order to validate the structure. A classical rupture criterion is enough efficient to predict the limit load. 


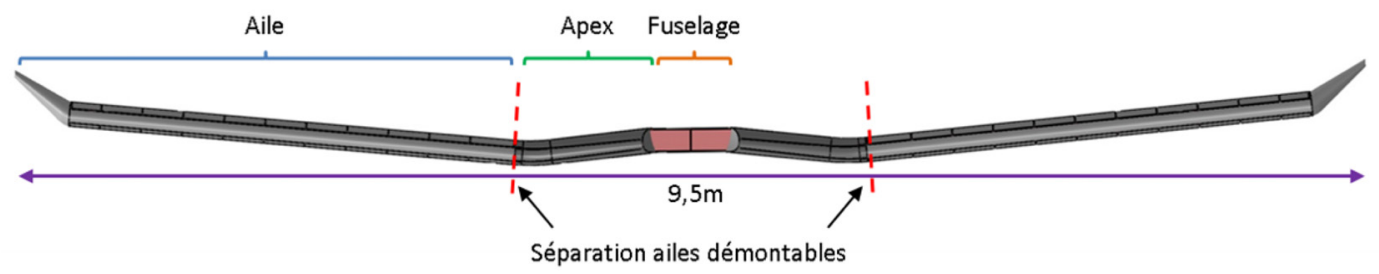

Fig. 3. Schematization of E-Fan wing architecture.

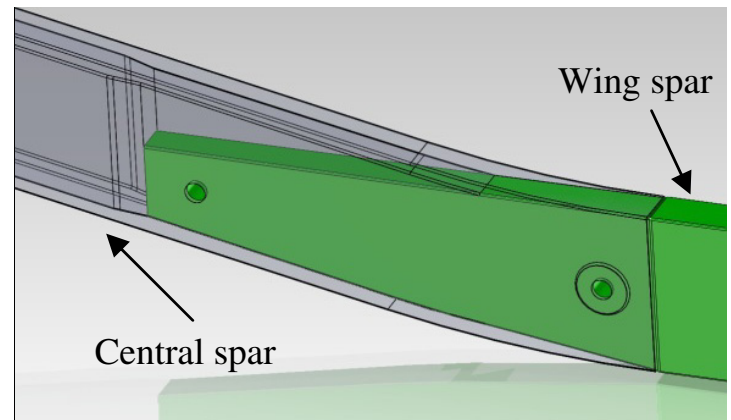

(a)

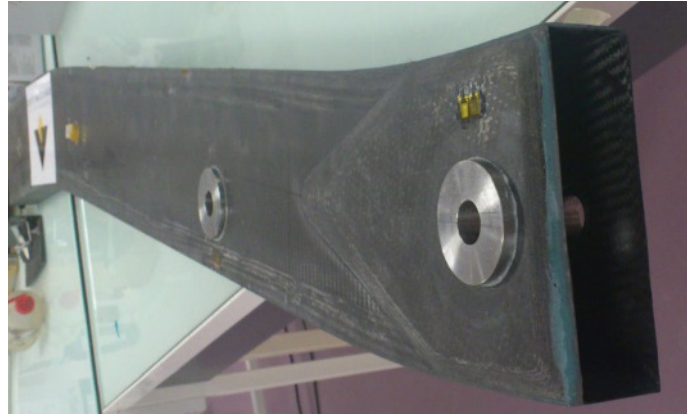

(b)

Fig. 4. (a) Representation of the spars fit system and (b) photography of central spar tip.

\subsection{Choice of architecture}

E-Fan prototype 1.0. presents the same constraints like all aircrafts using this kind of propulsion. To locate the batteries in the apex as shown in Figure 2, involves two criteria for the design of the wings: the structure weight and the internal space thereof. Indeed, in order to board the maximum batteries without increasing the airplane weight, the structure should be light. Moreover, it should have compartments which can contain the batteries.

In Europe, the aerobatic aircraft has to support maximum load factors of $+6 \mathrm{~g}$ and $-4 \mathrm{~g}$.

During a flight, the lift from the wings balances the aircraft weight. The lift and the drag are generated by a pressure distribution which can be easily computed by taking into account the wing profile along the cord and the wingspan. In order to validate the structure by DGAC, it is necessary to verify the aircraft integrity under a load factor which is Gravity $(g)$ multiplied by a coefficient $(x)$. For an amateur-built aerobatics plane, this coefficient is equal to 6 for aluminum plane, and equal to 12 for composite plane. In this framework, a pressure is applied on the wing by balancing the aircraft weight under a gravity field which is equal to $x$ multiplied by Gravity $(g)$. Consequently, the drag is also in the same order of magnitude. This coefficient allows to easily take into account the acceleration effect on a structure.

DGAC dictates to us to keep classical architecture for E-Fan wing. So, a single spar must be able to support the lift as defined in the standards. For E-Fan prototype 1.0, this spar is supplemented by two false spars respectively located on trailing edge and leading edge. Both complementary spars involve the resumption of torsional loads in the plane of the wing.
E-Fan central spar is fixed in the fuselage by pins in according to a classical principle in general aviation. The W-shape of the wing chosen by the designers simplifies and reduces the weight of the retractable landing gear. The batteries are stored in the wing close to the fuselage called apex (Fig. 3). The apex ends with a dihedral modifications before the interface with the dismountable parts of wing. Only the complete spar has to support the efforts, so the wing spar has to be directly connected to the central spar. This configuration makes complex the design because the connection is located between the apex and the wing at the root, and not in the fuselage as usually done. However, the connection design is determined by the batteries location and by the dihedral modification of the apex shape. Indeed, the available space reduces the number of possible geometries. Moreover, mounting as dismantling must be easy and fast without clearance.

The spars are $160 \mathrm{~mm}$ high and $90 \mathrm{~mm}$ wide because of the batteries storage into each apex. The central spar, the wing spar and their fasteners must be respectively integrated in this latter dimension (Fig. 4). Consequently, a fit system of the wing spars is designed into the central spar. In this connection, the loads transmission is ensured by two titanium adjusted pins (Fig. 4). The wing spar ends with a trapezoidal shape in order to fit together with the central spar tip (specific manufacturing method). This geometry fixation ensures the mounting without clearance and without difficulty. The lack of space maximizes the insertion length constrained by the curvature radius of the center spar. The mechanical principle of this removable junction is reliable.

The small dimensions imposed by the wing shape and the connection between the central and wing spars lead to define a box section for them. This design allows easily to respect the specifications in terms of size and load flow. 


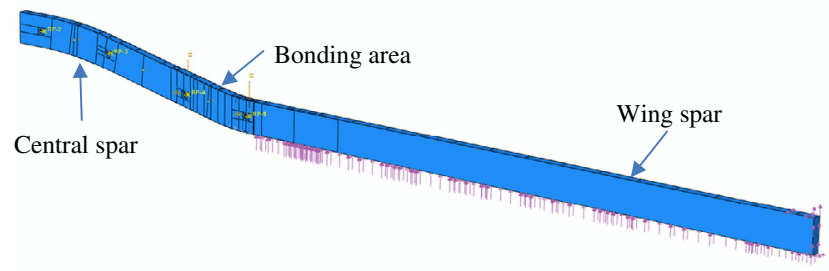

Fig. 5. Numerical model of the wing spar and the apex spar.

Moreover, the composite manufacturing process is realizable. This design maximizes the moment of inertia with a reduced weight. This carbon box consists firstly of two flanges which support bending loads and secondly webs which transmit the shear loads. A foam core is added to prevent the local buckling of the sidewalls. To minimize the weight of the wing spar, the thickness of both flanges decreases along the wingspan, so that they are loaded to iso-stress.

The numerical model has two separated parts which correspond respectively to the wing spar and the apex spar (Fig. 5). The spars are modeled in three dimensions; the dimensions are the theoretical values requested from the manufacturer. The core is represented by a 3D volume while the composite parts are some plates defined on the outer surface of the volume. The separated modeling of both spars allows to take into account the fit system and therefore, the connection between the spars. The numerical model building follows the confidential specific manufacturing method of C3Technologies. All composite plies are defined by their orientation and their thickness. Both spars are bonded by two pivot points corresponding to the pins. The loading is applied to the intrados side of the wing. The loading distribution is based on the approximate aerodynamic loading which is provided by the aircraft designers. The loadings from the winglet are added to the spar end. The boundary conditions for the apex spar are representative of the ones presented into the fuselage; two pivot pins avoid the transversal movement of the webs.

The wing model is built from the spar model. The ribs, the false spars and the skin are modeled with shells (Fig. 6). The real definition of composite plies is again implemented in the numerical model. All these parts are merged in order to reduce the computation time. Loadings due to the winglet are still applied on the spar. The wing aerodynamic loading is applied by pressure on the whole wing surface (lower and upper faces). This pressure comes from the aerodynamic computations on the 2D airfoil. The boundary conditions are provided by the spar pinning and the false spars, as in the case of the actual wing. However, in the numerical model, the spar is pinned to an infinitely rigid frame and the apex spar is not infinitely rigid in reality.

The pins and the inserts sizing includes the constraint of limited space in the spars. The inserts and the pins are made of titanium alloy TA6V in order to reduce galvanic corrosion with the carbon fibers. The caulking sizing is realized on metal parts by the conventional analytical

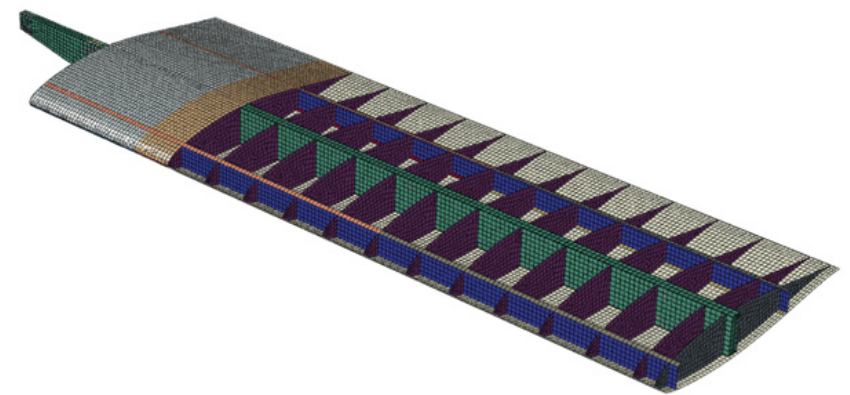

Fig. 6. Cut-view of the numerical model for the wing internal architecture.

Table 2. Comparison between analytical and numerical loadings in the pins.

\begin{tabular}{ccc}
\hline & Analytical $(\mathrm{N})$ & Numerical $(\mathrm{N})$ \\
\hline Pin 1, horizontal axis & -1073 & -632 \\
Pin 1, vertical axis & -52185 & -53030 \\
Pin 2, vertical axis & 41798 & 42455 \\
\hline
\end{tabular}

method. A specific analytical method is used for composite parts including inserts [12]. This method is based on a computation of homogenized elastic plate and it is validated for quasi-isotropic laminates. A stress concentration coefficient in according to the material and the geometry improves accuracy level. The loadings for the pin sizing are calculated by using the method imposed by DGAC (Table 2). This agency must be able to verify all computations of these critical parts of the airplane. The loadings values through the pins are verified by comparison with the numerical model.

The number of ribs, their thickness, their localization and the skin thickness are optimized to save low weight, strength and low shape deformation during the wing deflection. The standard referred to E-Fan certification does not define any formal design criterion. In literature, the works relate to the influences of the shape deformation between the ribs on wing performances. This work shows that more the profile warps more the drag increases. In Figure 7, for the same spar design and the same rib distribution, the plies number in the wing skin plays an important role in order to avoid the skin blistering phenomenon. So, a compromise about ribs and skin design is determined in relation with the wing deformation and the low structure weight.

For design and good mechanical behavior of the wing, the most important element is the spar and its connection. The numerical model is built with the real geometry and the material data identified from samples. As a result that the structure complexity cannot rely on a sufficiently robust analytical computations, DGAC requires to perform a test on the complete spars in order to certify E-FAN wings. Before making this final validation step, semi-structure tests are performed. They allow to validate the manufacturing process in order to obtain a good structure strength and stiffness; to validate the level of the predictive numerical model and; to prepare the testing of the complete spars structure. 


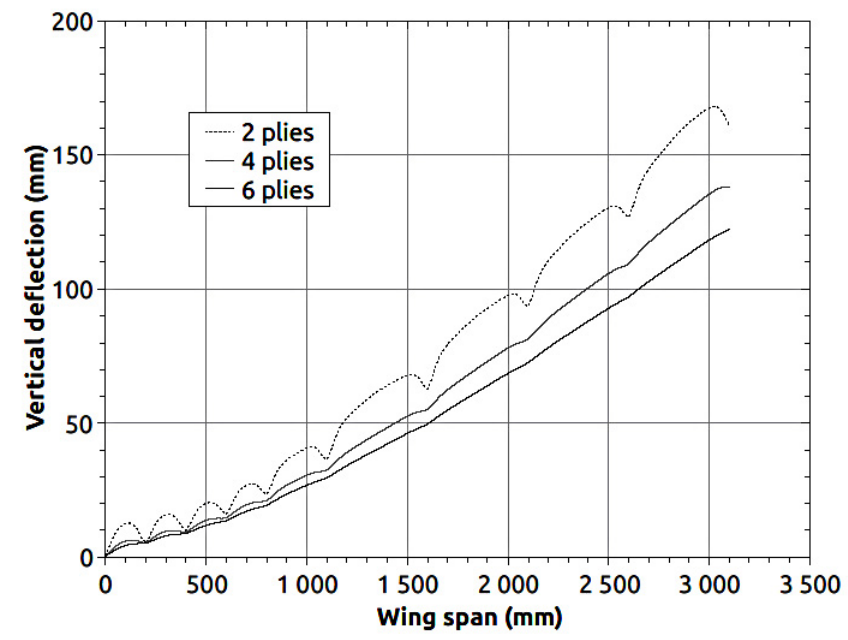

Fig. 7. Plies number influence on the shape deformation for the wing skin.

\section{Experimental validation of the spar numerical model}

\subsection{Semi-structure tests: 4 points bending test}

\subsubsection{Trial description}

As previously, the raw materials are distributed by Structil: prepregs $\left(300\right.$ g.m ${ }^{-2}$ ) with TR50 carbon fibers and with an R367-2 epoxyde matrix. The core material is C70-75 PVC foam provided by Airex.

The test consists of a four-points bending on a spar section, with a constant flange thickness. The length of this section and the thickness of his flanges are sized to retain acceptable dimensions and limit the local punching. Two tests are performed: the first test is carried out on a tensile testing machine equipped with a specific bending bench.

In Figure 8, the tools for 4 point bending test are constituted of a bottom part of $1.2 \mathrm{~m}$ long and an upper part of $0.4 \mathrm{~m}$ long. Supports are $90 \mathrm{~mm}$ high and $25 \mathrm{~mm}$ diameter. Aluminum plates are bonded to the composite beam in order to locally limit the punching due to cylindrical supports of bending bench. Testing speed is $2 \mathrm{~mm} . \mathrm{s}^{-1}$.

The second test is performed on a structure bench (Fig. 9). The distances between supports are the same as the previous ones on the tensile testing machine. Aluminum stirrups with glass-epoxy composite plates located at the interface with the spar, allow to distribute loading points along the structure. They are connected from the spar to the test bench by chains. The stirrups are specifically developed and sized for the spar test. The tooling stiffness decreases in opposite to the one of tensile machine and can involve a testing geometry modification. Indeed, the stirrups are clamped on the section and they cannot slide; the spar bending brings closer the external supports and takes away the inner supports. These movements alter the chains direction and the force direction imposed on the spar; however, the changes are low.
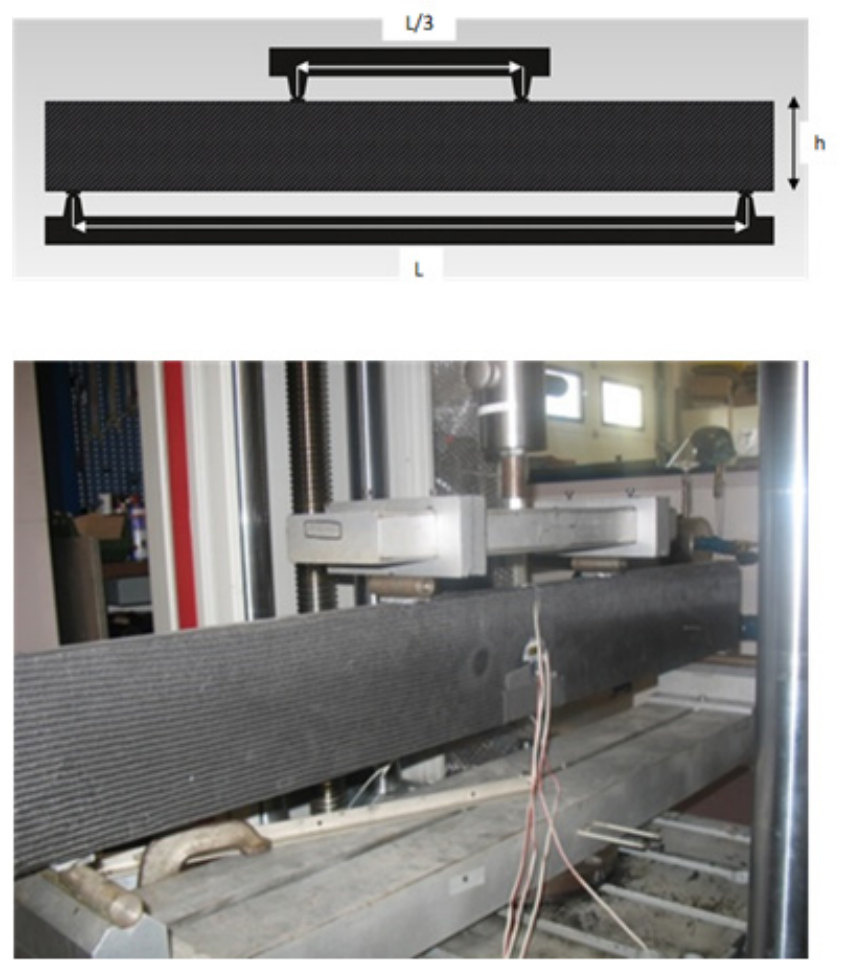

Fig. 8. Tools for 4 points bending test on a tensile testing machine.

Glass-epoxy composite plates are used to avoid local punching of the composite spar.

\subsubsection{Metrology description}

A local metrology is installed in addition to measured elements (displacement and force) in order to correlate the numerical simulation with the testing results. The main goal is to compare the strains measured in different zones of the structure with the ones from numerical model. This specific metrology is constituted of four strain gauges: a unidirectional gauge located on each flange and a bidirectional gauge located on each side. Each gauge is located on the outer surface and, at the same wingspan for both web and flange sides.

A draw-wire sensor is placed at the middle of the spar span, at the bottom flange in order to immediately measure the maximum deflection.

On a static test bench (Fig. 9), the draw-wire sensor is fixed on the spreader in order to measure the imposed displacement of the load points.

\subsubsection{Results presentation}

During the first performed test, severe punching is observed at low load (Fig. 10). The perforation occurred at the fillet between the web and the flange. This phenomenon can be explained by the very small thickness of the webs and by the sharp edges of aluminum plates. So, 
C. Fleuret et al.: Mechanics \& Industry 17, 614 (2016)

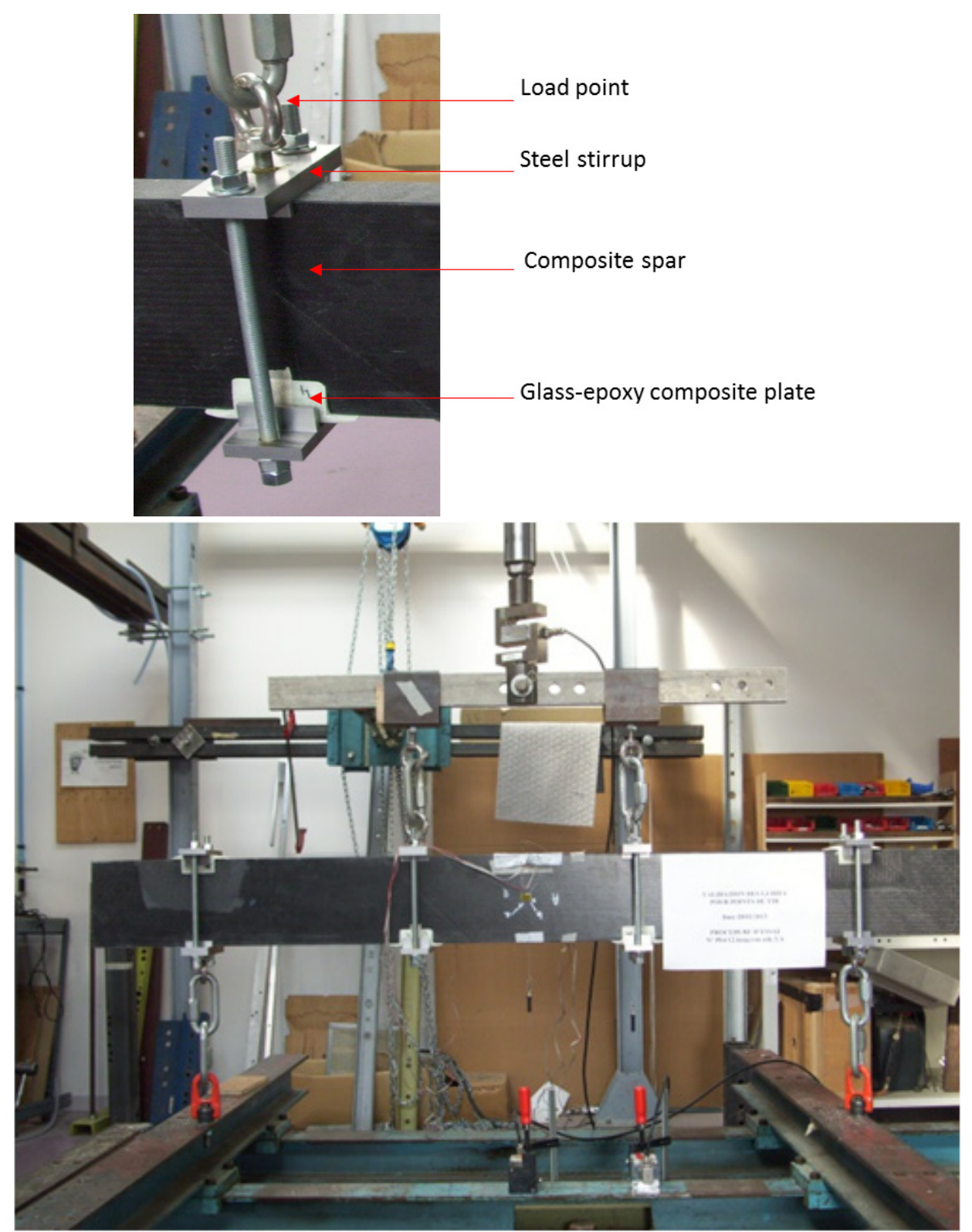

Fig. 9. Modified tools for the spar test on structure test bench.

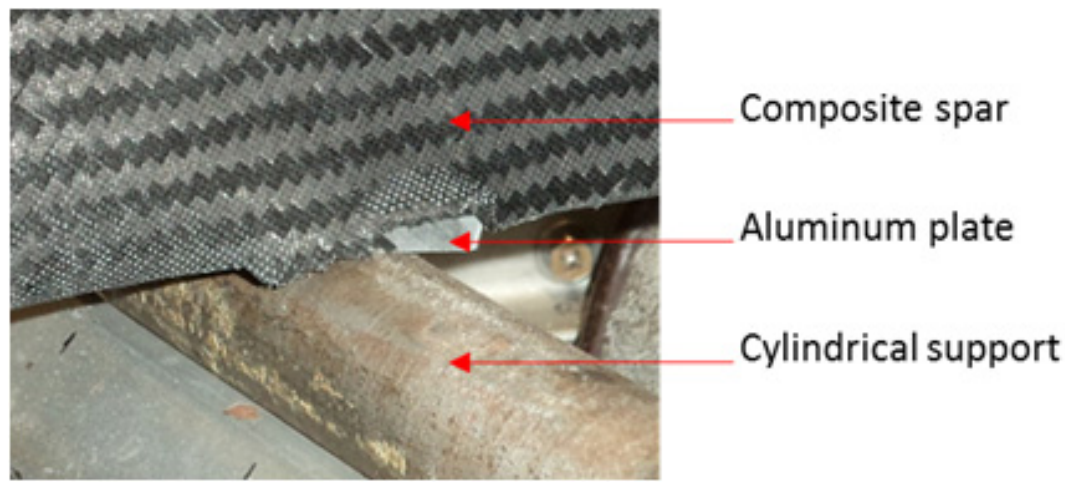

Fig. 10. Spar test fixture on tensile machine and fracture by punching. 


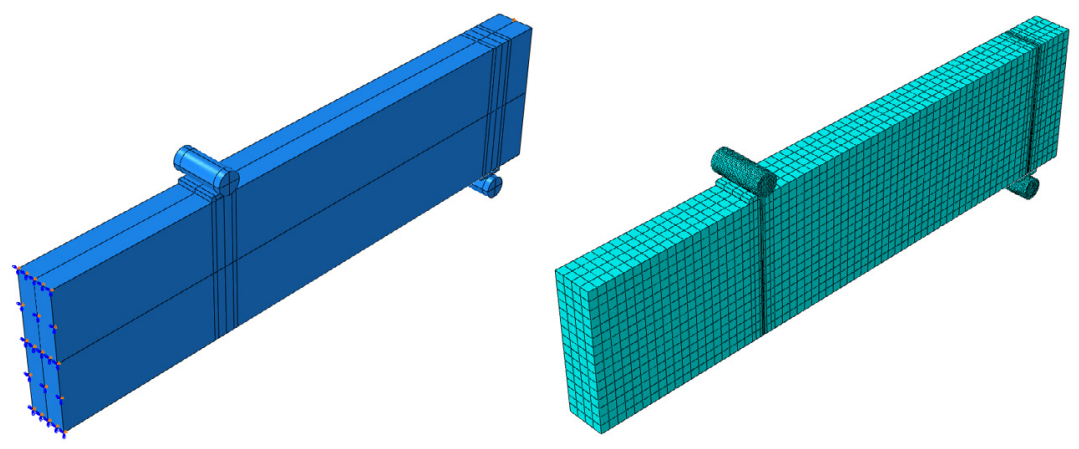

Fig. 11. 4-points bending numerical model.

for spar certification, the method of the first test is given up.

For the second test, the new tools allow to bear a higher loading than the previous ones without observing any known damage. The forces values at each stirrup exceed more than three times the maximum expected load during the structure test. In this configuration, the testing was led up to the maximum capacity of the force sensor $(30000 \mathrm{~N})$, the rupture did not occur.

\subsection{Experimental/numerical correlation of the 4-points bending test on semi-structure}

\subsubsection{Numerical computation description}

The numerical model of 4-points bending is built in three dimensions, it represents the configuration for the first test (Fig. 8). This model is similar to the full spar model. A 3D volume with the theoretical dimensions of the specimen is defined for which the core material is applied. The outer faces of this volume serve to support shells which are carbon-epoxy composite. The thicknesses of the composite model is measured by micrograph of a test beam. The ply stacking is defined by their orientation. Only half of the beam is represented by imposing a symmetry condition which reduces the computation time (Fig. 11). The supports are cylindrical like the ones for the test on tensile testing machine. The aluminum plates at beam/cylindrical support interface are modeled in order to avoid local punching. Computations are driven by imposing displacement in according to the test. Carbonepoxy composite material properties are provided from sample tests and the core material properties from literature. All material behavior laws are linear elastic. The contact between steel cylindrical supports and aluminum plates is modeled by the Lagrangian multiplier method. The mesh consists of C3D8 and S4R elements of $10 \mathrm{~mm}$ with bias reducing this size to $0.6 \mathrm{~mm}$ at the supports. Computations are made with nonlinear geometry method.

\subsubsection{Confrontation and analysis}

In Figure 12, the curves represent the deflection obtained at the middle of the spar respectively by both tests

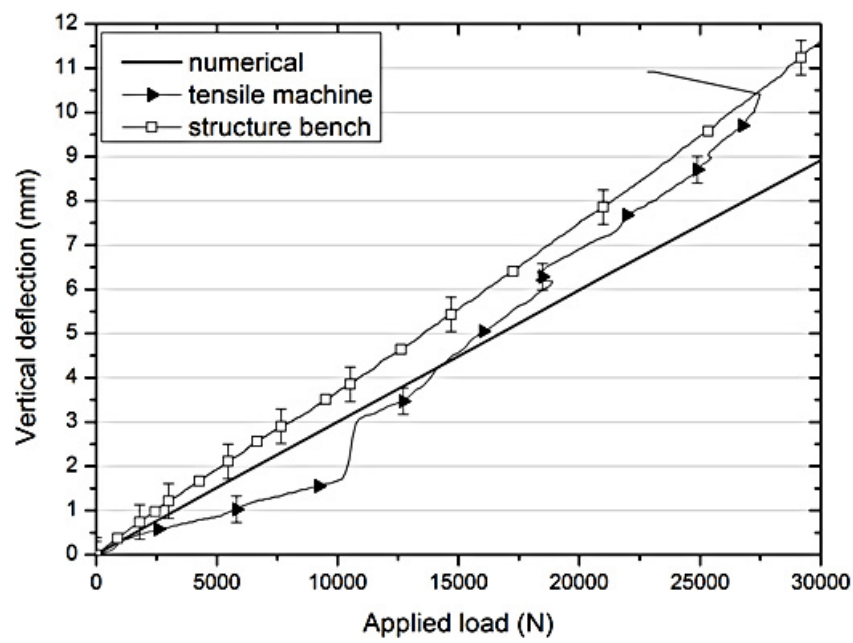

Fig. 12. Comparison of deflection at the middle of the spar respectively numerically obtained and experimentally measured.

and the numerical model. The numerical deflection has a lower slope of approximately $21 \%$ than the one obtained by the structure bench test but, greater than the one on tensile testing machine. The numerical model has a similar stiffness as the tensile machine test at low loading. In fact, the modifications of behavior occur at low loadings. The measurement accuracy of the draw-wire sensors is low, so it is difficult to judge the numerical-experimental correlation at the beginning of the experimental results. The test bench has a different tool; the testing geometry is changed continuously because of the ties which induce a change in behavior. The measured deflection is nonlinear. In addition, the geometry modification involves a margin of error for deflection measurement.

Despite this difference for the deflection behavior in relation with loading, numerically calculated strains are consistent with those ones measured by strain gauges. This result reflects the good modeling of the global kinematics of the spar and the ability of the hybrid model (3D volume and shells) to estimate strain fields (Fig. 13). For the flanges, the correlation between measured and calculated strains is good. For the webs, the correlation results is sufficient between the test with cylindrical support and numerical computations. 


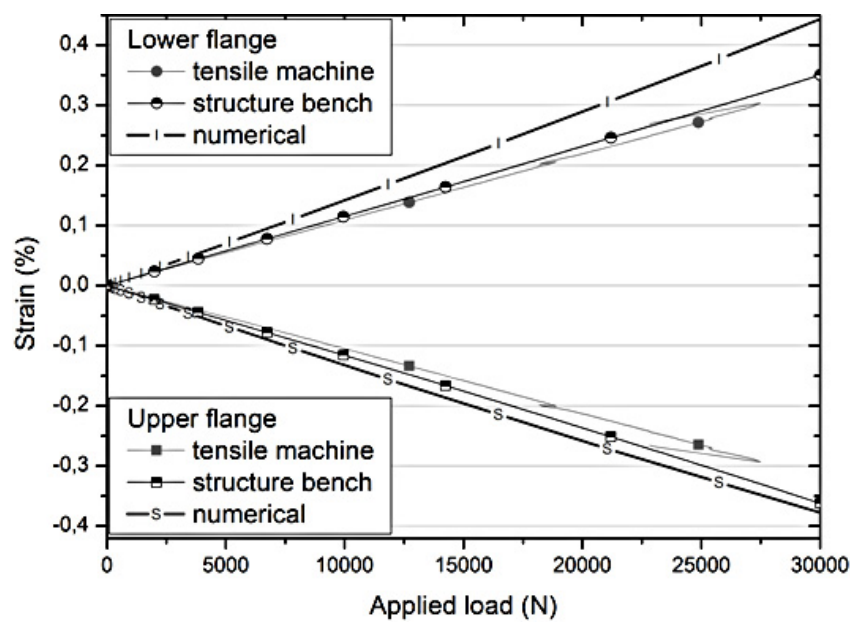

Fig. 13. Strain at the center of upper and lower flanges in according to the applied force.

The four points bending tests allow us firstly to adjust and validate the tooling for the complete spar test, and secondly to validate the hybrid $3 \mathrm{D}$ numerical model of the spar. These tests have also led us to modify the spar manufacturing method in order to increase the loading transfer between the flange and the web.

\section{Spar structure qualification}

\subsection{Test on structure: Apex-Wing spars assembly}

The assembly of both longitudinal spars (the central spar and the wing spar) is called structure. The objective of this final static test is to validate the sizing of the central and the wing spars and the connection between these two spars in order to meet the specifications imposed by DGAC. It imposes a first limit load test without damage followed by a second destructive test in order to verify the structural integrity save at the ultimate load. The structure test is a static unsymmetrical bending test until rupture, no matter the incipient failure areas. The maximum reached load before rupture conditions the flight envelope authorization given by DGAC. A delegation ensures the results authenticity.

\subsubsection{Test setting up}

The central spar is fixed by two pins on test bench. The tooling for central spar pinout is designed so as to create infinitely rigid conditions to the root, then the test is conservative in view of actual conditions. The wing spar is fixed to the central spar with the system previously sized.

The test principle is shown in Figure 14. The central spar and the wing spar have together 8 load points. This load distribution is representative of aerodynamic loading; it minimizes the tools number and the necessary space. Indeed, the available tools allow to use a single jack and so, a whiffle-tree is defined as shown in Figure 14. The choice of spreader location allows to impose the forces due to the winglet, without that the last stirrup being too close to the spar end. Stirrups location and spreader lengths are calculated by imposing a load close to the actual aerodynamic loading (Fig. 15). The dihedral of apex and wing are different, so pulleys are used to correct angles. They are located so that the connecting cables are normal to the spars when the load factor reaches 9 g. As a reminder, two tests are carried out on the test bench: the first is up to limit load $6 \mathrm{~g}$ and, the second is up to rupture load which is superior to $6 \mathrm{~g}$. The setting is made to suit both tests. Furthermore, spreader lengths and pulleys positions are determined by taking into account displacement and deformation of the structure in order to ensure the proper alignment of the whiffle-tree to $9 \mathrm{~g}$ loading. Lastly, the top spreader is previously inclined so as to be orthogonal to the cable and the jack at $9 \mathrm{~g}$ loading. The spreaders are balanced by taking into account stirrups weight to avoid inducing no extra loading to the spar.

The structure width is smaller than the length, so during the test, it is necessary to provide a guide in order to avoid structure dumping. Guides are distributed along the spar span, three of them hold the wing spar and two others hold the central spar (Fig. 16).

\subsubsection{Test instrumentation}

During the tests, the structure is instrumented by four kinds of sensors, as shown in Figure 17:

- 6 strain gauges groups are located on the spars. Each group is constituted of an unidirectional gauge on each flange and a bidirectional gauge on each web (orange arrows in Fig. 17)

- 3 draw-wire sensors are arranged on the spars, one at each end of the wing spar and the central spar (green arrows in Fig. 17),

- 2 force sensors are used, the first one is positioned under the jack, it measures the total force applied to the structure, the second one is located at the first stirrup (Fig. 17) to verify the correct load balancing,

- Acoustic emission sensors are arranged between the gauges of groups 4 and 5, on the upper flange in order to measure the activity close to spars connection. Acoustic emission sensors are spaced $130 \mathrm{~mm}$ and they are coupled to the wing spar with a silicone adhesive. Acoustic emission sensors reliably detect and locate damages initiation (like matrix cracking, delamination and fiber breakage,...) and monitor crack progression. Acoustic waves are mechanical waves which travel through the structure when it is loaded. Indeed, each damage or deformation corresponds to a phenomenon of elastic energy release by the way of transitional elastic waves into the material. Acoustic wave intensity is related to amplitude $(\mathrm{dB})$. More the wave amplitude is high, more the displacement is high, more the sound intensity is loud. The detection threshold of acoustic waves is $30 \mathrm{~dB}$. 


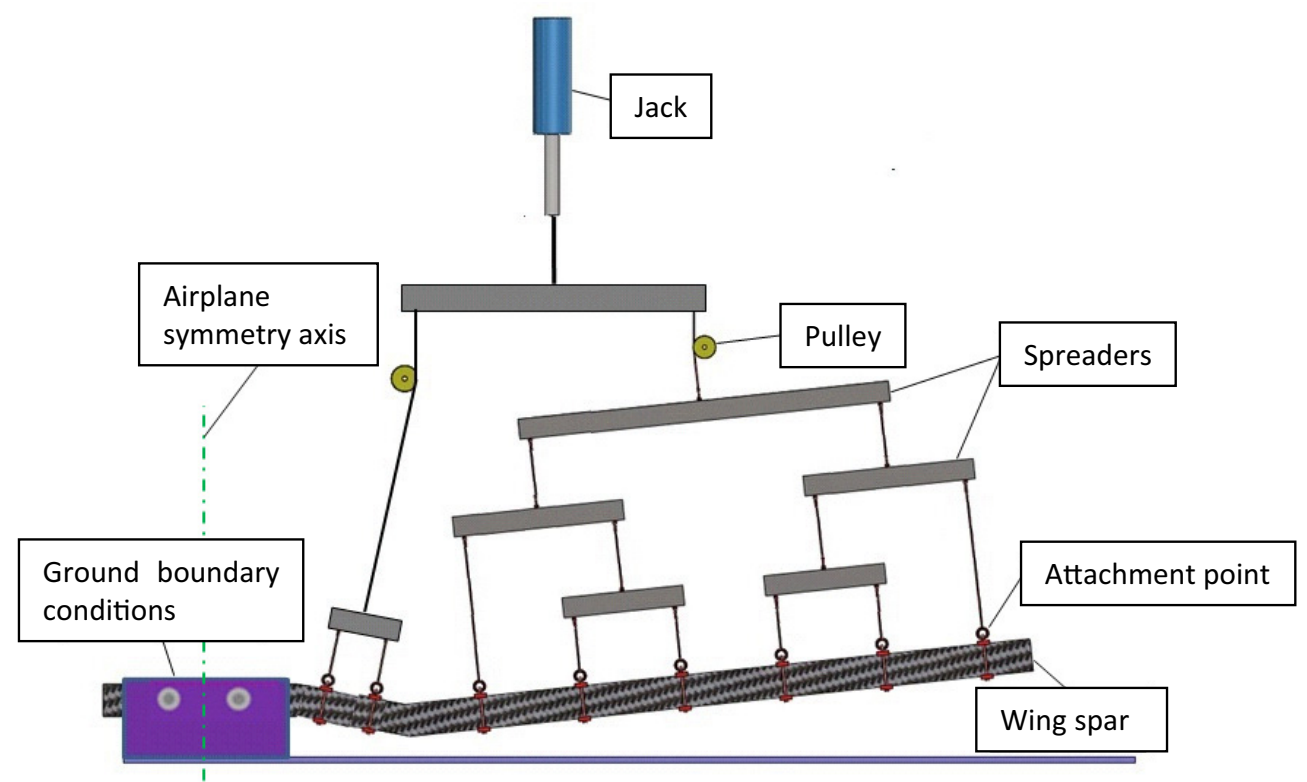

Fig. 14. Scheme of the whiffle-tree for structure testing.

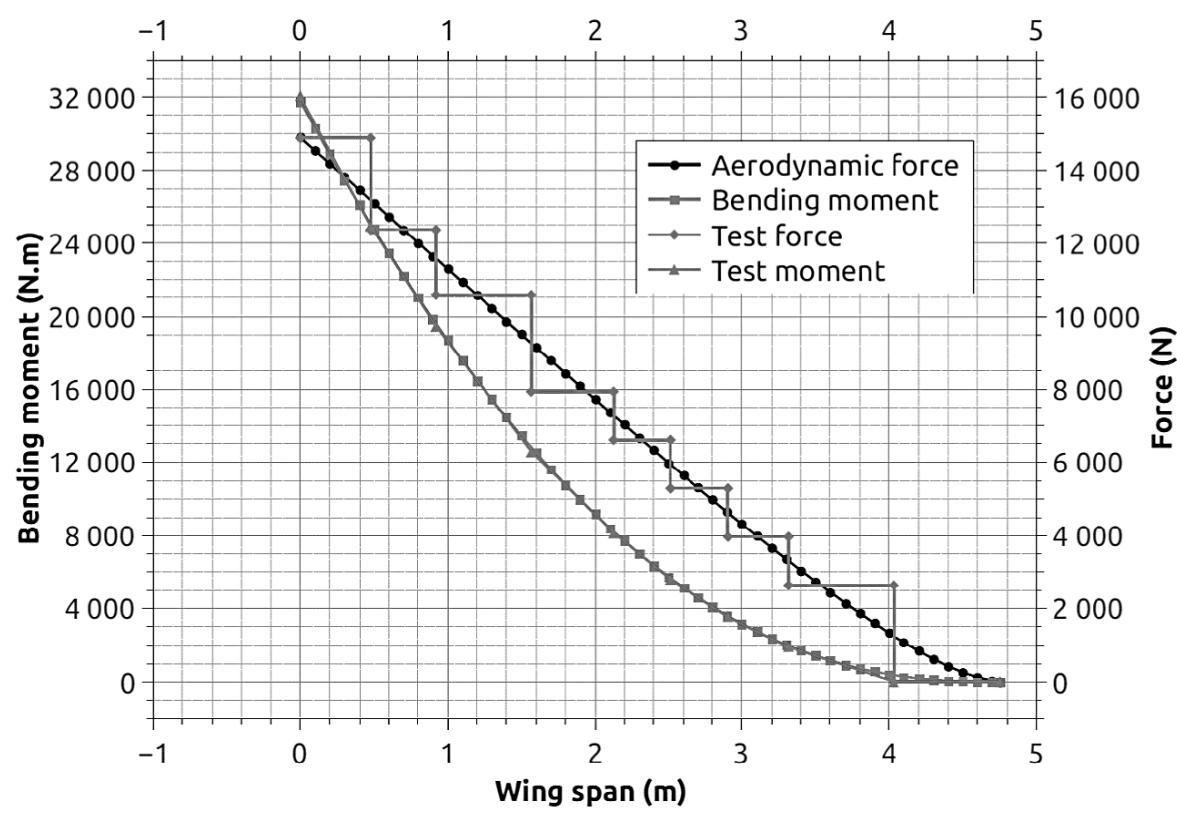

Fig. 15. Comparison between the aerodynamic loading and the loading enforced by the whiffle-tree.

\subsubsection{Structure test loading}

DGAC's specifications impose two loadings applied to the same structure:

- Test 1: rise up to the limit load test $(6 \mathrm{~g})$ is driven by step, by adding $10 \%$ of load to each step, with a pause time of $3 \mathrm{~s}$ at each step. Once $6 \mathrm{~g}$ step is achieved, a slow discharge is operated.

- Test 2: a destructive test is realized with a first continue loading rise until the limit load $(6 \mathrm{~g})$, from which the incremental loading method is repeated until failure (Fig. 18).

\subsubsection{Results and analysis of the test}

The first test up to the limit load shows that the good correction of spreader lengths.

The second test confirms the good spreader correction and the pulley location. The rupture came at $9.3 \mathrm{~g}$, it means 1.55 times the limit load while it was expected 2 times the limit load, so $12 \mathrm{~g}$.

During the first test, a light acoustic activity is observed in an average amplitude range. On the second loading, it is not recorded acoustic emission before reaching the previous load at $6 \mathrm{~g}$ which checks Kaiser effect [13-20] 
C. Fleuret et al.: Mechanics \& Industry 17, 614 (2016)

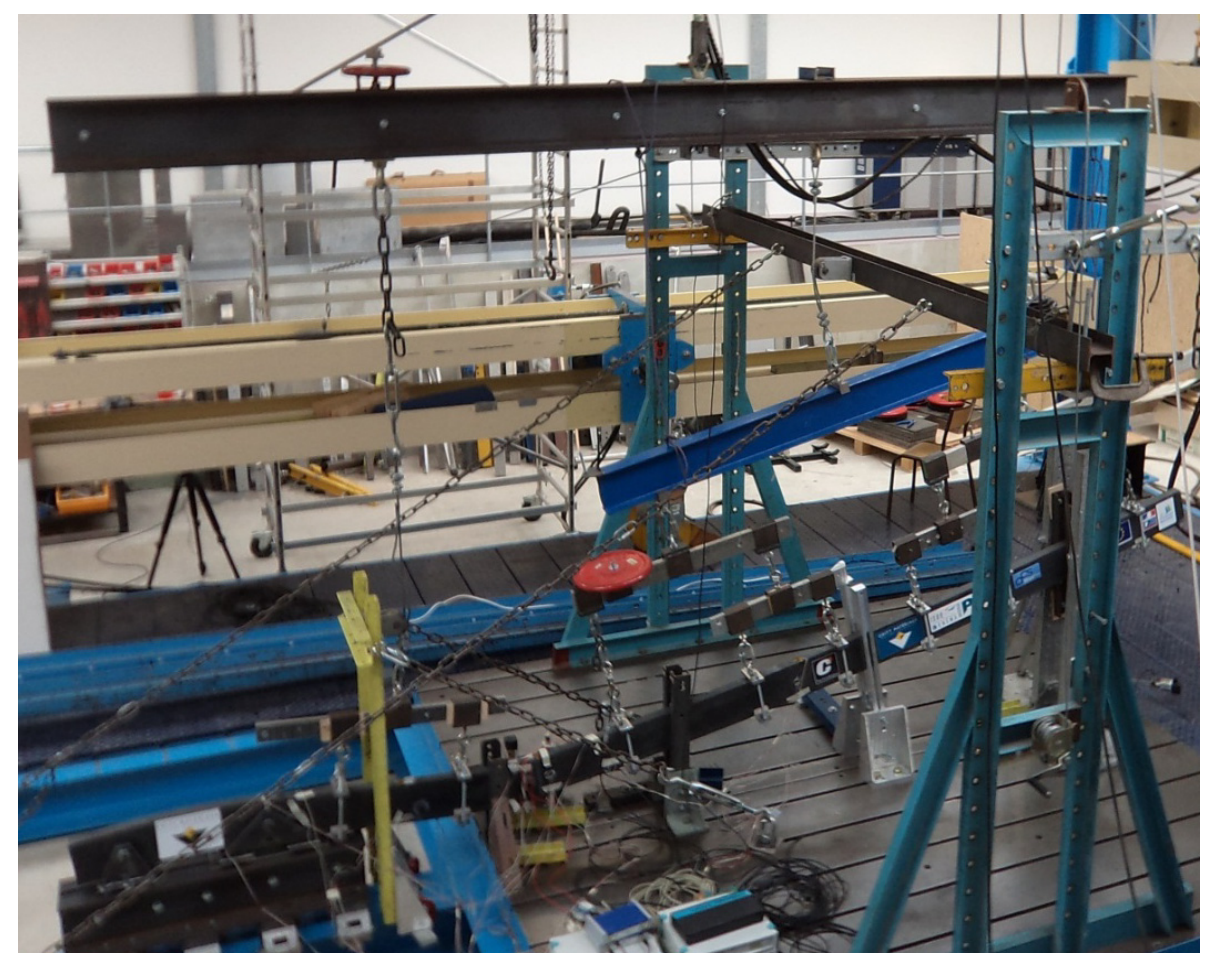

Fig. 16. Test assembly of central and wing spars with the guides.

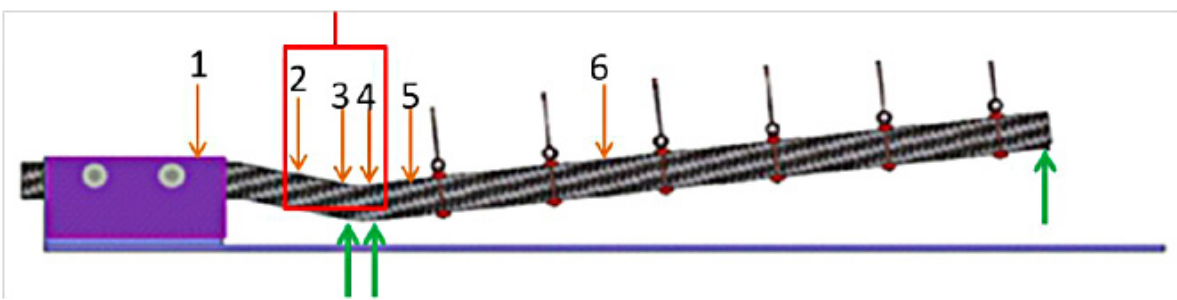

Fig. 17. Illustration of instrumentation sensors on the complete spar.

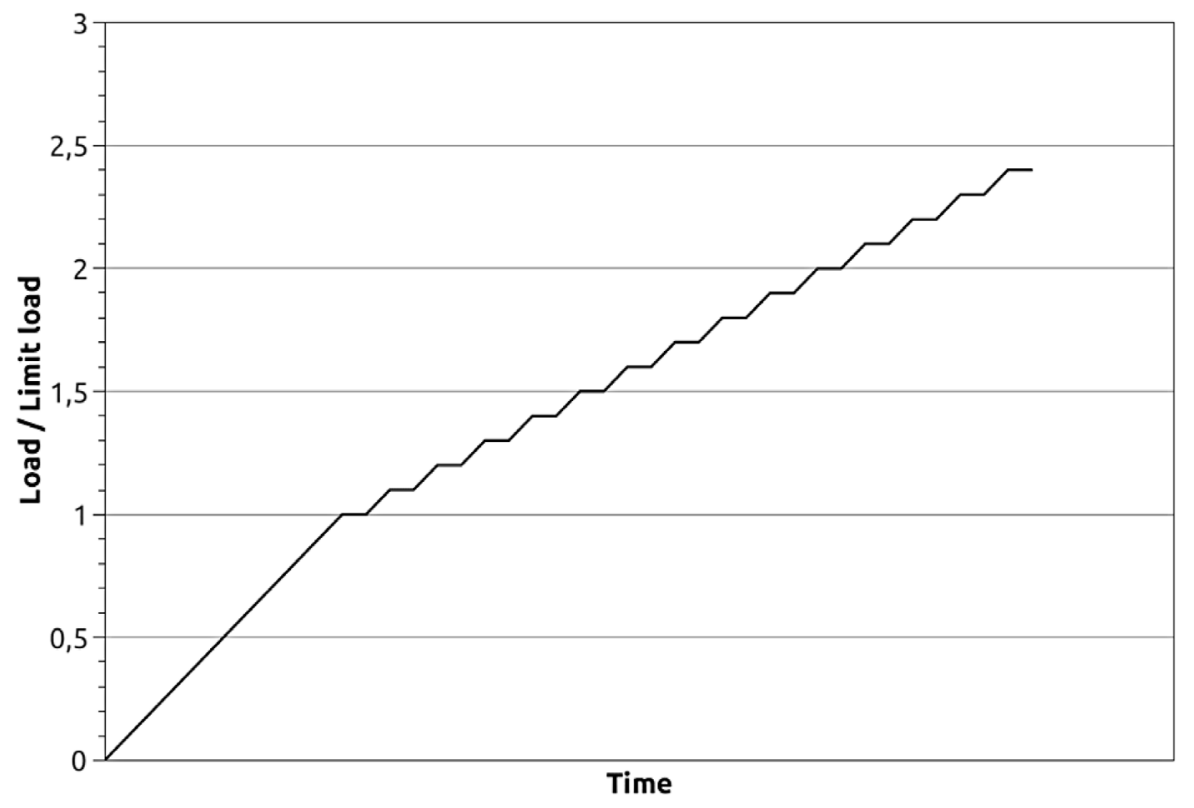

Fig. 18. Loading method for the test until structure failure. 


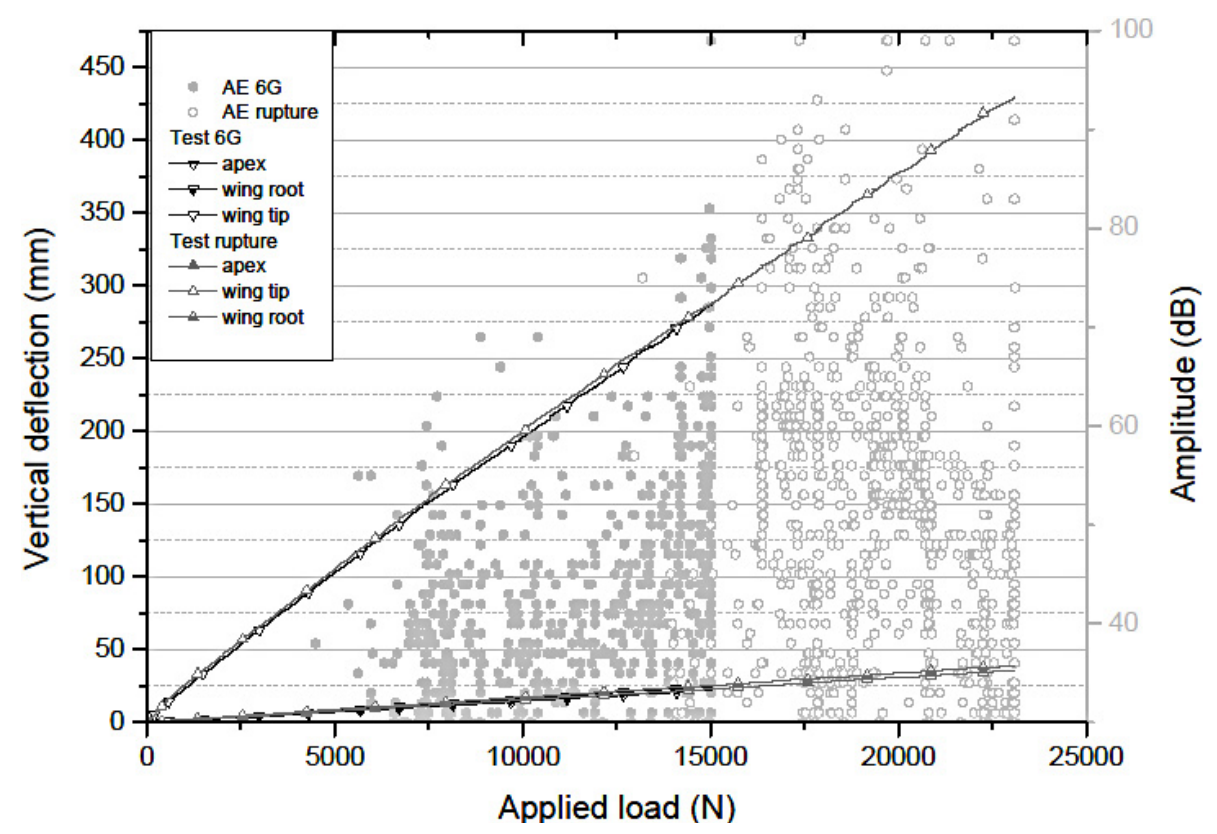

Fig. 19. Bending test of the spars, deflection of wing and central spars in according to the applied load (AE: Acoustic Emission).

(Fig. 19); in other words, no damage is detected before the limit load $6 \mathrm{~g}$.

Rupture is located just after the location of gauges group 5 and acoustic emission sensor 2 on the wing spar.

The localization of acoustic events just before rupture corresponds to the damage area that leads to the final fracture (Fig. 20). In addition, the precipitated acoustic events are in high amplitude range, which corresponds to fiber breakage.

After the second test, several kinds of fracture are visible: buckling of a web, tear of the other web and compression breaking of the top flange (Fig. 21). Fracture on the upper flange is located at substantially close to the edge of steel stirrup.

Both tests show a good correspondence of forcedisplacement and stress-strain curves until the limit load. During the second test, the acoustic activity absence up to the limit load indicates no creation of a strong damage, the correct spars sizing is confirmed until the limit load (Fig. 19).

However, the wing spar rupture occurs before the load threshold referred to $12 \mathrm{~g}$.

Three failure factors have been identified from the fracture surfaces of wing spar: a lack of foam bonding at foam/web interface for a one side; the high thickness reduction of unidirectional layers on upper and lower flanges close to the stirrup and; the local spar punching by the stirrup.

Following the observation of web buckling, the bond between the carbon laminate and the foam presents a low shear strength for a one web side of the spar. In Figure $22 \mathrm{a}$, on this entire web length (checking conducted at several points), adhesive rupture is presented at carbon laminate-foam interface, contrary to the other spar web (Fig. 22b). This phenomenon exists only for the side which is cured by autoclave. The peel ply holds some release agents, which are not normally transferred to the object, but this phenomenon is possible when the laminate is cured at high temperature and, especially into autoclave.

Furthermore, two strong thickness modifications are located in the rupture area, the web thickness is from $0.66 \mathrm{~mm}$ to $0.44 \mathrm{~mm}$ and the unidirectional flange is reduced from $5.27 \mathrm{~mm}$ to $4.65 \mathrm{~mm}$. These thickness decreases involve an important stress variations in this area.

In addition to these factors, the stirrups are held in position by clamping. Glass-polyester laminates and elastomer plates are used to avoid contact between the metal stirrup and composite spars. Despite this precaution, a local punching is possible due to the tightening and the local deformation of the wing spar.

The coupling of the three factors: buckling of a web, tear of the other web and compression breaking of the top flange, explains the failure apparitions at a premature load below the expected ultimate load.

\subsection{Test/simulation correlation of the joining strength}

\subsubsection{Simulation presentation}

The numerical model used to make the correlation is the same geometry model which is used for spars sizing. The geometry is the same as the complete spar for the structure test (Fig. 23). It is also composed of two beams: the central spar and the wing spar which are joined together by pivot connections. The central spar is embedded to the frame by two pivot connections (pins) in order to prevent spars spillage, when boundary conditions are imposed at the guides. 


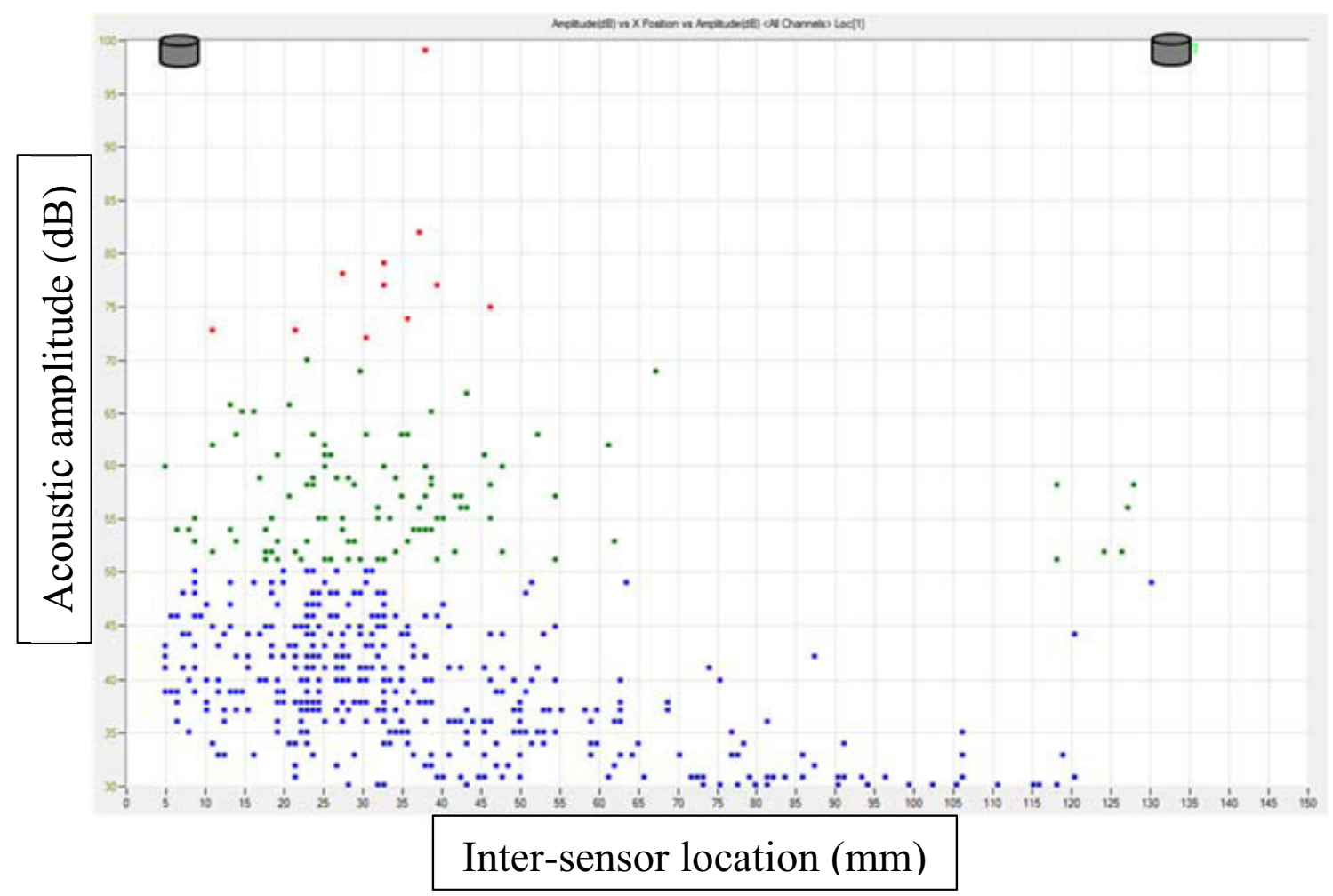

(a)

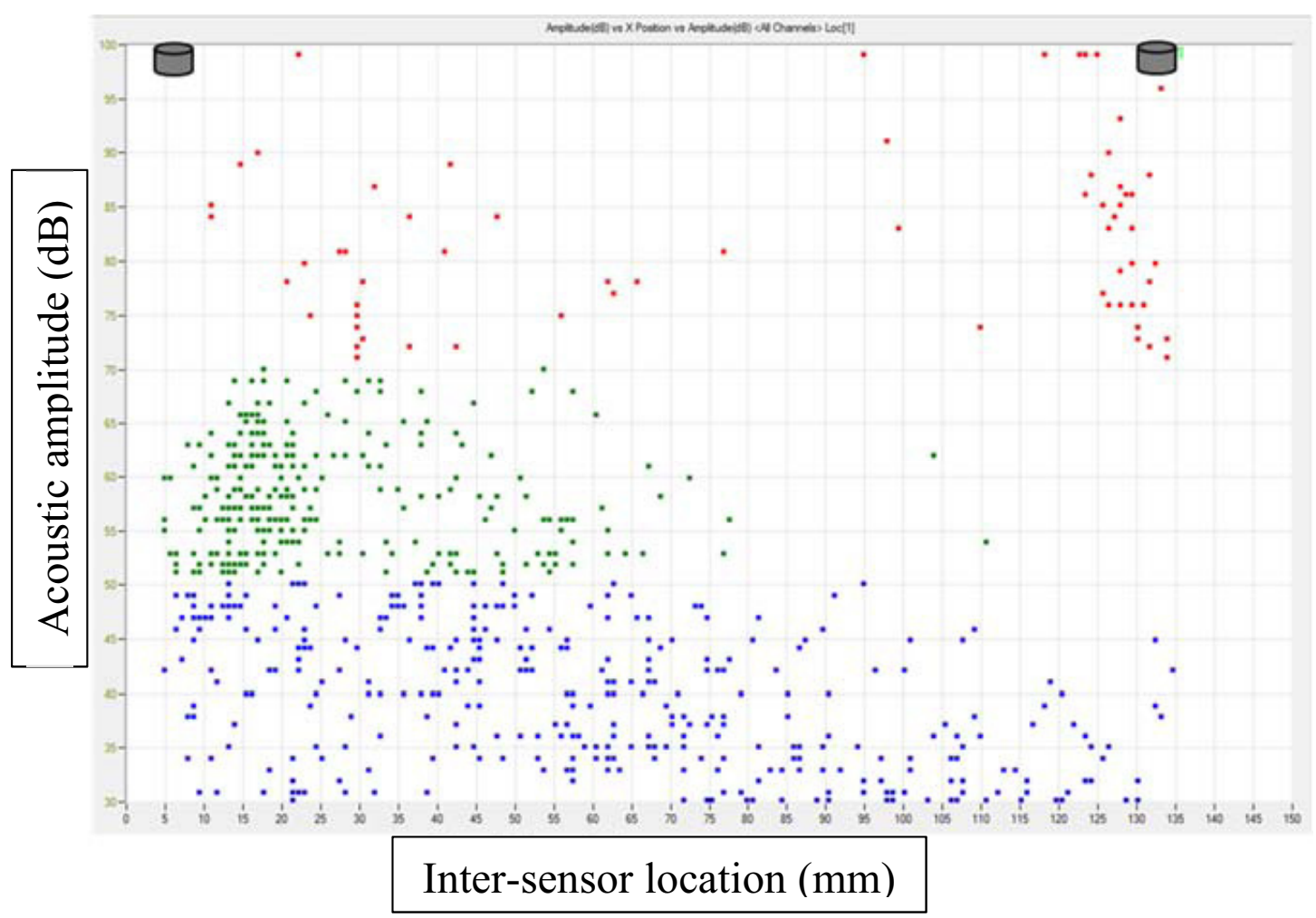

(b)

Fig. 20. Bending test of the spars: amplitude of acoustic events in according to their inter-sensor location. (a) Test 1 , (b) test 2 . 

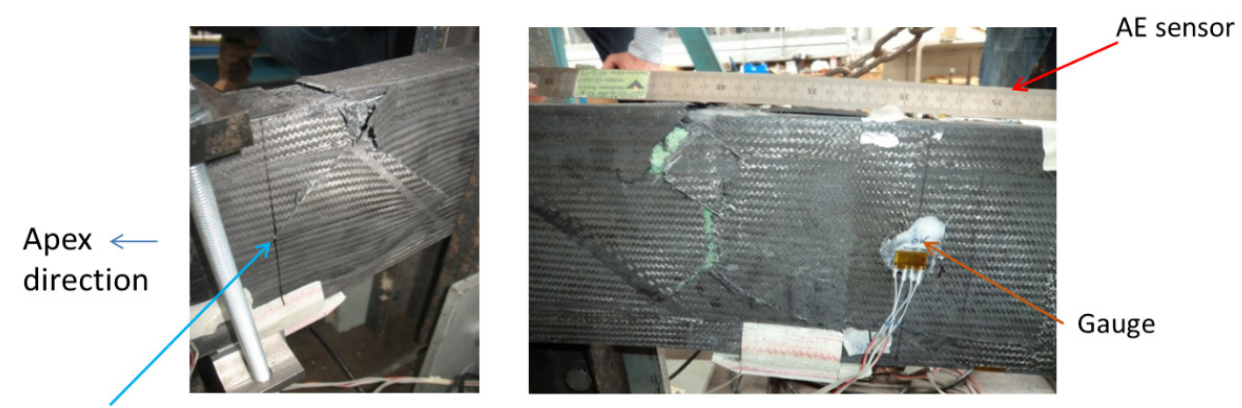

Initial axis of the stirrup

Fig. 21. Photography of the web rupture of each wing spar.

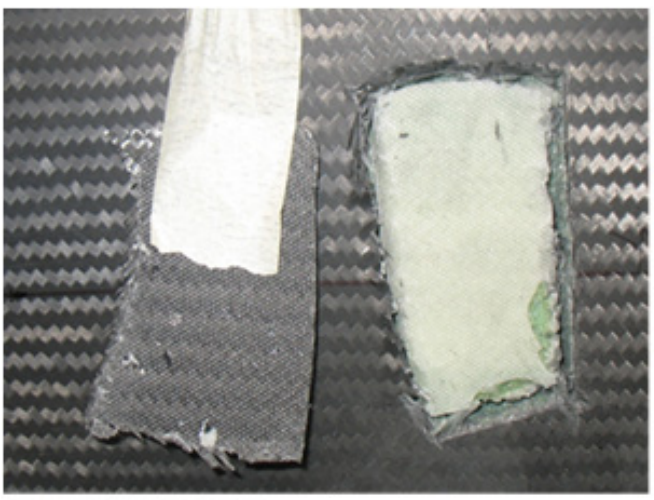

(a)

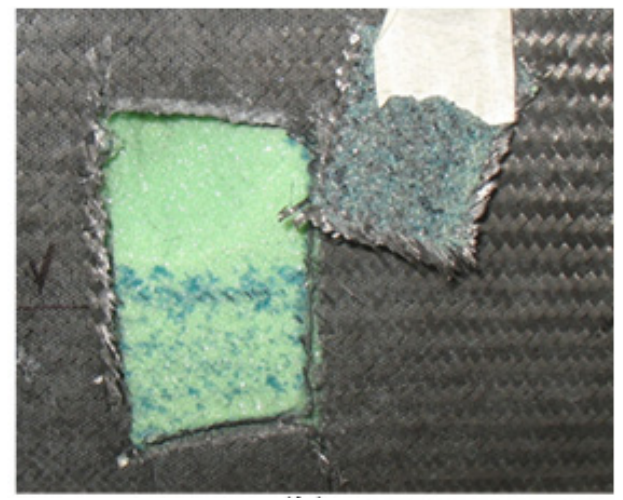

(b)

Fig. 22. Photographs of adhesion difference between both webs.

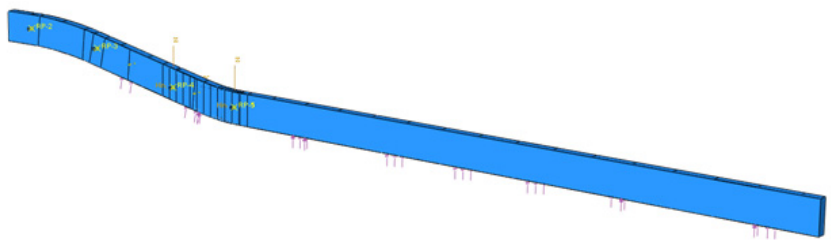

Fig. 23. Numerical model of the test spars.

The loading used to make test/simulation correlation is the same as the experimental one, it means the same 8 load points located from the same place along the spar span.

\subsubsection{Confrontation and analysis}

The numerical model accuracy must be verified by correlations with experimental results for deflection and strains. Below, all graphs have a maximum abscissa of $25000 \mathrm{~N}$ which correspond to $10 \mathrm{~g}$, while the rupture came at $9.3 \mathrm{~g}$.

In Figure 24, a good correlation of the wing spar end deflection is shown between test and numerical model. The second graph shows a focus of the curves representative at the wing spar root. The gap between simulated and measured results is greater at the root, the result deviation is about $20 \%$.
Strains extracted from the numerical model are correlated with the ones measured by strain gauges. Numerical strains during loading are calculated at the nodes which correspond to the gauges location. In Figure 25, a good correlation is shown between the flange strains. In Figure 26, for the web strains, a slope difference is about $30 \%$ between the values recorded in the test and the values of the numerical model. In Figure 27, numerical simulation is conservative compared to the test results for the flanges strains.

The numerical values of strain near wing/apex connection should be just an approximation. Indeed, this area is highly stressed with a very high stress gradient. Moreover, in this area, modeling by shell elements is not representative because of the continuous thickness variation of the real spar.

After the structure test, the comprehension of the spar rupture scenario is necessary in order to optimize the predictive level of spar numerical model. As previously in Section 4.1.4, several factors can be a source of spar failure.

Firstly, the stress fields from the model with loading applied continuously along the wingspan and the same model loaded by 8 load points show a very high similarity. A local difference is only observable in the load introduction zones. This result confirms the accurate distribution of shooting points and, the quality of test assembly. 

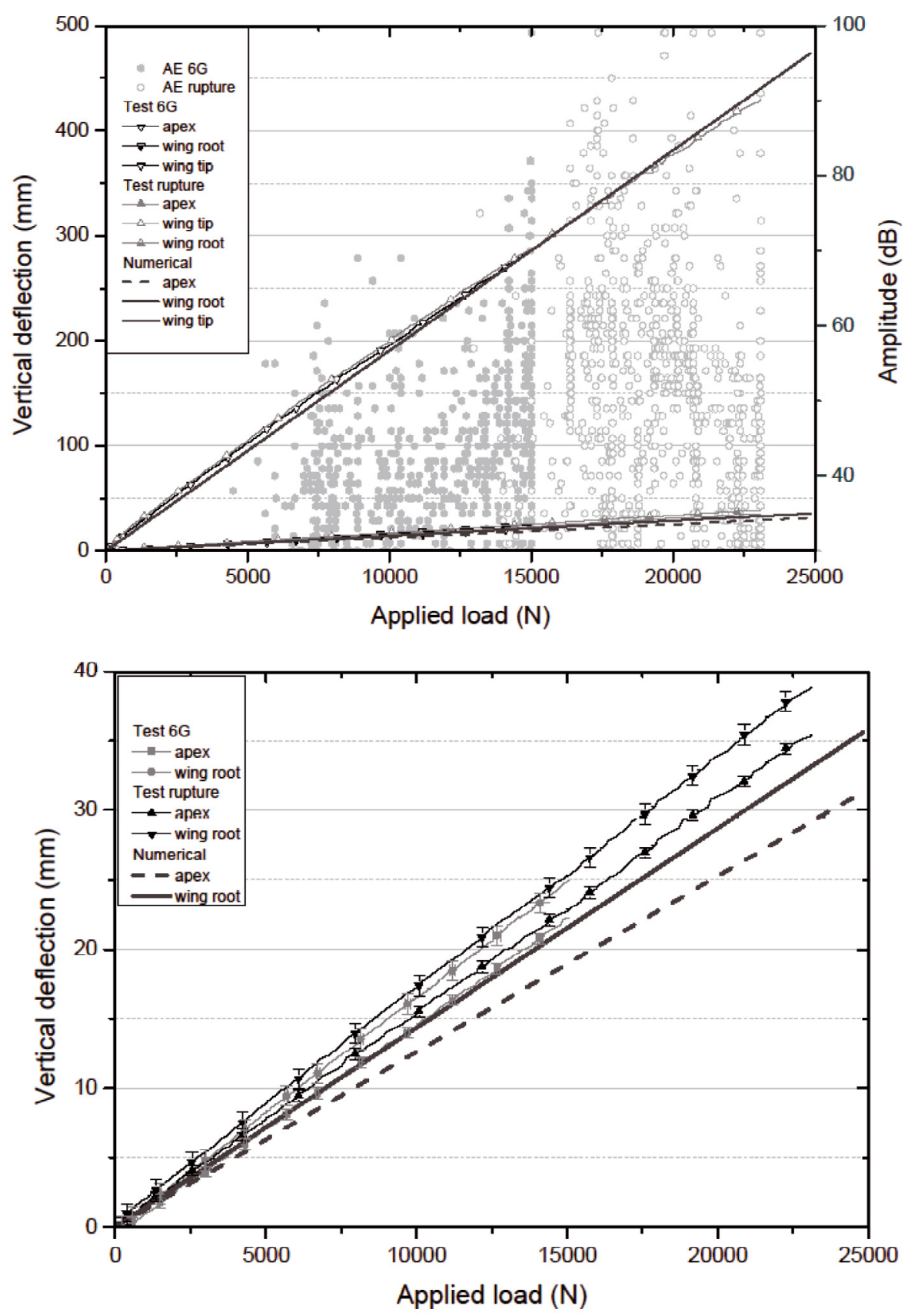

Fig. 24. Graphs representative of spars deflection in according to the force.

Secondly, three successive modifications are made to the spar nearby the fracture area in order to understand rupture scenario. Web delamination and web buckling are implemented into the model by reducing local stiffness properties close to the failure load. This change causes a slight increase of the stress at the stirrup and near the "buckling" area. However, this stress increase does not explain the spar failure at this location.

In order to approach the real spar geometry, discretization of the finite element flanges is increased. Indeed, the flange discretization was $200 \mathrm{~mm}$ intervals for sizing, so great thickness changes is presented between each section (Fig. 28), ply number of flange is reduced from 29 to 17 in the failure area.

The numerical model is modified by a discretization of $40 \mathrm{~mm}$ in the rupture zone. This discretization change into model reduces the stress concentration between thickness variations and, locates the maximum stress at the failure area (Fig. 29).

However, the stress level remains under the laminate strength. A final calculation is used to assess the influence of the stirrup clamping on the spar. The clamp value is very difficult to determine because of the complex tools. Several tests with different torque (Table 3) show only 


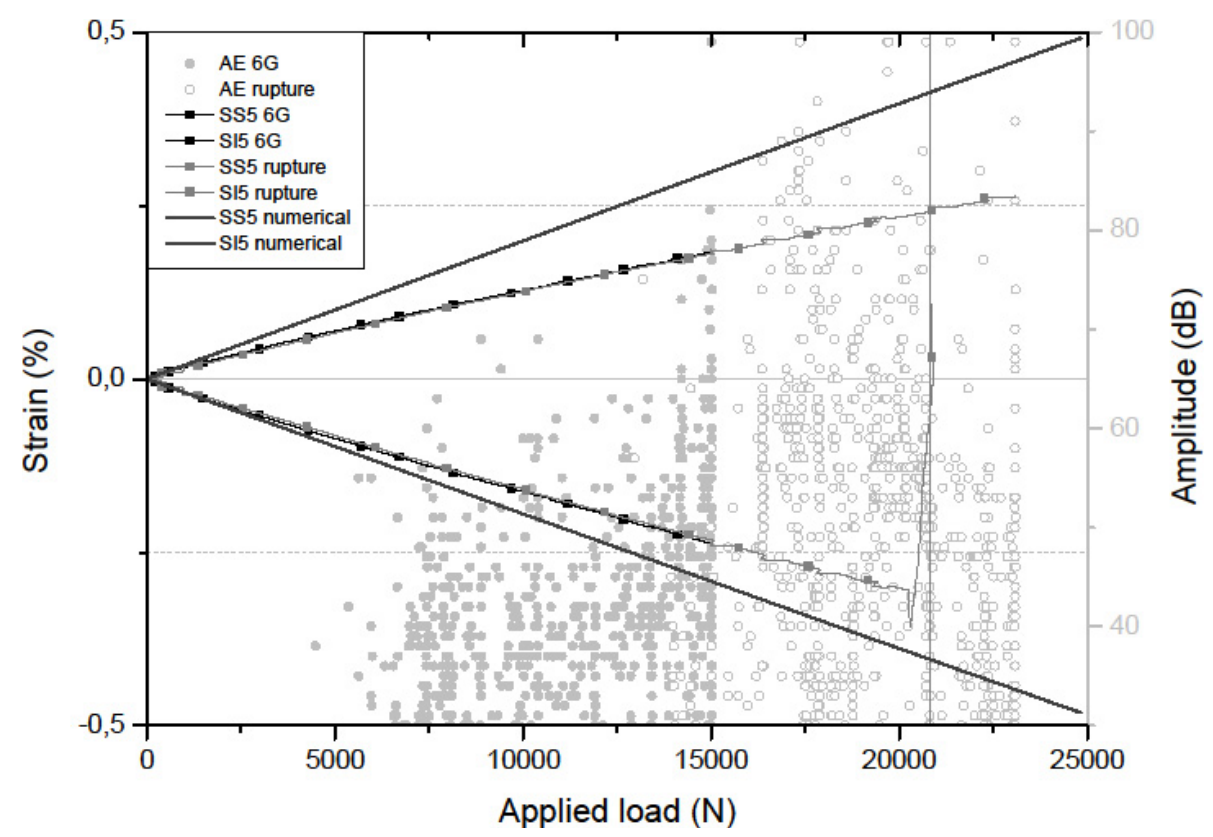

Fig. 25. Experimental-numerical correlation graph of the flange group No. 5 strain.

that some significant tightenings allow to reach the material strength (Fig. 30). But it is highly unlikely to reach these clamp values for this application.

During manufacturing process, the laminate thickness after compaction was not checked. Indeed, a high ply number involves a final laminate thickness smaller than the predictive one because of compaction. A section decrease is possible with an increase of fiber volume fraction, so the influence of the compaction phenomenon is difficult to quantify about laminate strength.

Comprehension of the mechanical behavior and the failure scenario of the complete spar is difficult after the structure test. Indeed, three failure sources are identified but, each of them cannot explain the rupture at the ultimate load alone. Moreover, the spar rupture appears at a premature load which is lower than the expected one. To conclude, the most probable rupture scenario is governed by the coupling of a strong tightening combined with the material properties variability and a strong laminate compaction.

\section{Conclusions}

The dismountable wing of E-Fan aircraft is a multimaterials structure with a complex geometry. The spars connection design respects the weight constraint, the transfer of the load levels reached in aerobatics by taking into account DGAC's specifications and the manufacturing process. This structure design is developed by following a progressive methodology in order to understand the mechanical behavior and the failure modes. The model building and the testing mastery are acquired by correlating experimental and numerical results of the small structures testing.
Firstly, the small structures testing allow to adjust and to validate the tooling for the complete spar test. Some specific tools are developed in order to limit the punching at the load points and to apply a representative loading distribution with the good boundary conditions. Secondly, these semi structures tests have also led to modify the spar manufacturing method. Some slight modifications of the bonding process and the internal spar structure are made in order to increase the loading transfer between flange and web. Then, hybrid 3D numerical model is validated by the correlation between experimental and numerical results of the semi structures. So, the complete spar and the connection are sized by the hybrid 3D numerical model.

E-FAN prototype 1.0 spar is qualified by an asymmetrical bending test on a structure testing bench with a specific whiffle-tree. Following DGAC's requirements, the spar rupture appears at a premature load which is lower than the expected one. Experimental/numerical correlations show a fairly good prediction. However, the rupture scenario is difficult to explain by the numerical model modifications. The most probable rupture scenario is the coupling of a local punching combined with a material properties variability and a strong laminate compaction. Consequently, some manufacturing modifications have been performed on the final parts to improve the mechanical strength and to consolidate safety beyond the required limit load.

Finally, E-FAN prototype 1.0 has obtained the license to fly from DGAC with a restricted flight envelop. This aircraft has made several flights since the structure test.

Acknowledgements. This work integrates the development program of E-Fan project. E-Fan is a electric Aircraft designed by Airbus Group Innovation and Aéro Composites Saintonges 


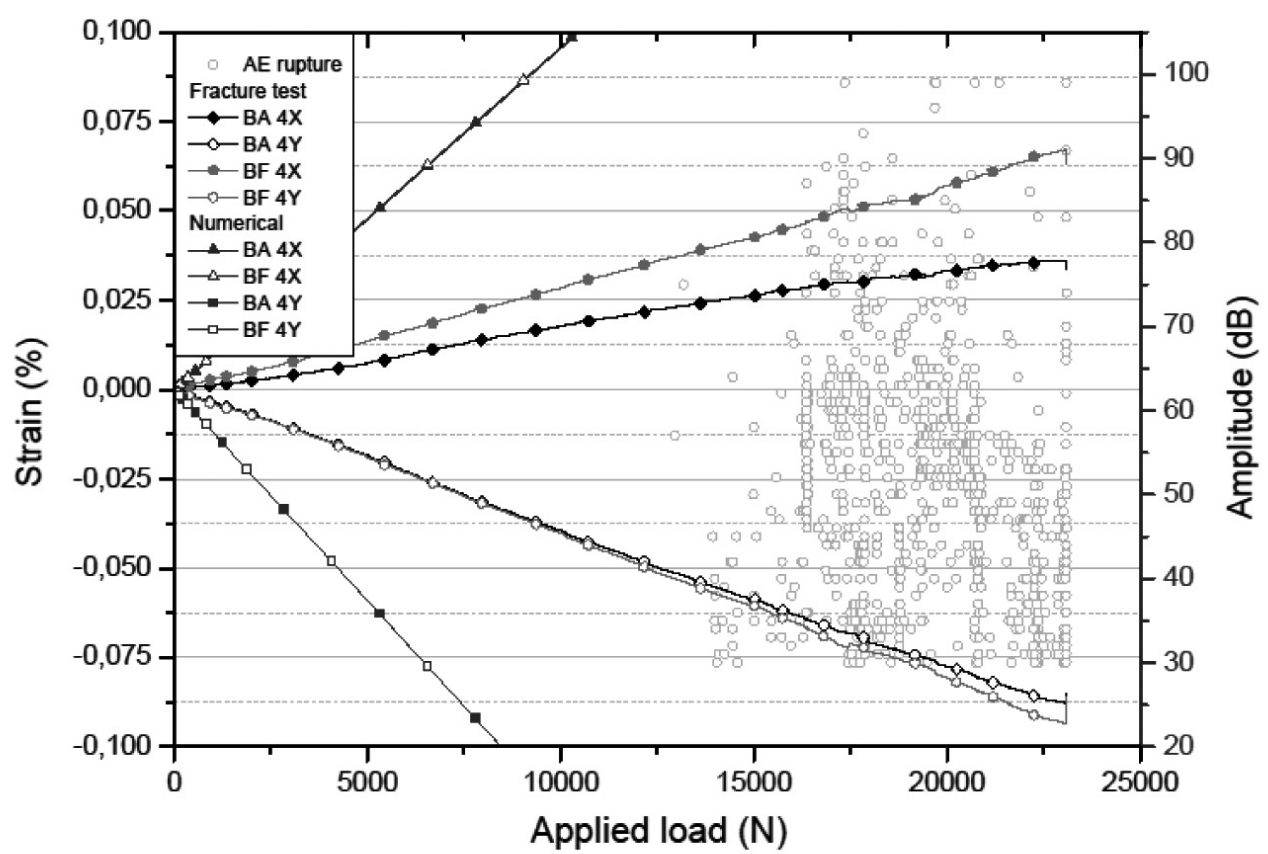

(a)

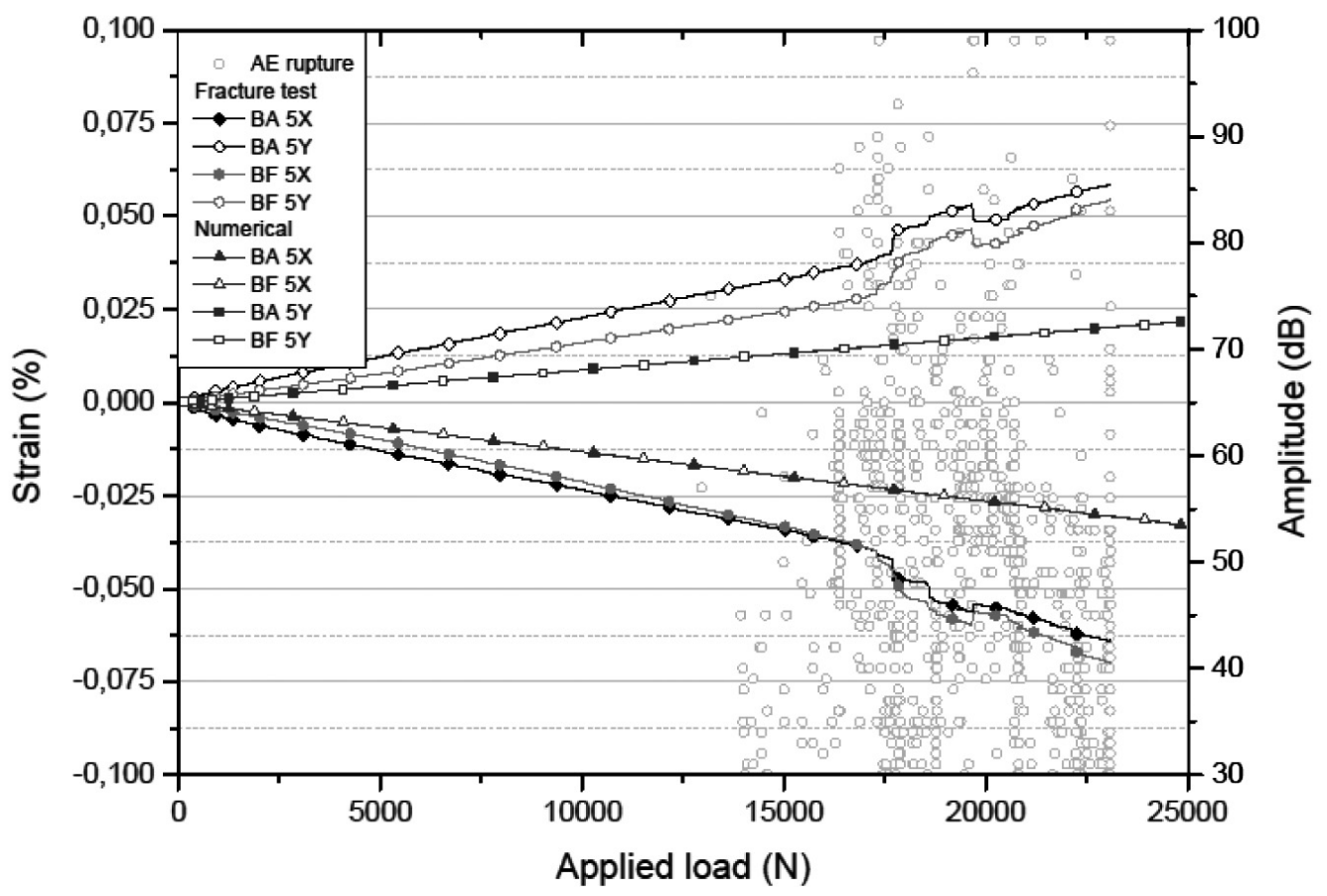

(b)

Fig. 26. Experimental-numerical correlation - strains measured on webs by group 4 (a) and 5 (b) gauge in according to the force.

Table 3. Influence of the clamp value on the maximal stress in the flange.

\begin{tabular}{cc}
\hline Clamp value & Maximum stress \\
\hline $0 \mathrm{~N}$ & $-602.807 \mathrm{MPa}$ \\
$1000 \mathrm{~N}$ & $-606.739 \mathrm{MPa}$ \\
$10000 \mathrm{~N}$ & $-691.586 \mathrm{MPa}$ \\
$20000 \mathrm{~N}$ & $-815.576 \mathrm{MPa}$ \\
\hline
\end{tabular}

(ACS). It is a 2 seats aircraft of $6.7 \mathrm{~m}$ length and $9.5 \mathrm{~m}$ span. E-Fan was presented at Paris Airshow by Airbus Group Innovation in 2013. This work was a part of the regional innovation project "Composite carbone aero". It was funded by FEDER, Etat-FRED and Poitou-Charentes. CRITT MPC was the project leader for the complete wing realization. This project was in partnership with the companies C3Technologies 


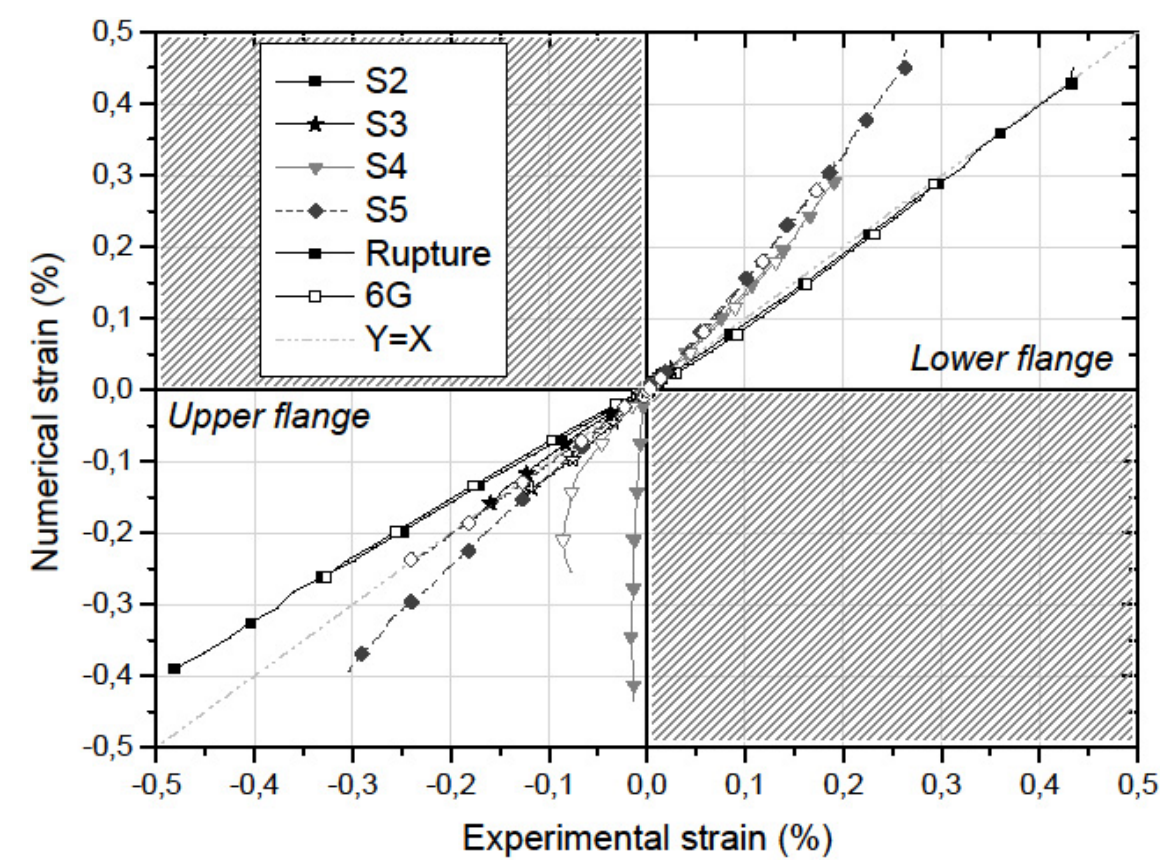

Fig. 27. Numerical strain - experimental strain measured on upper and lower flanges.

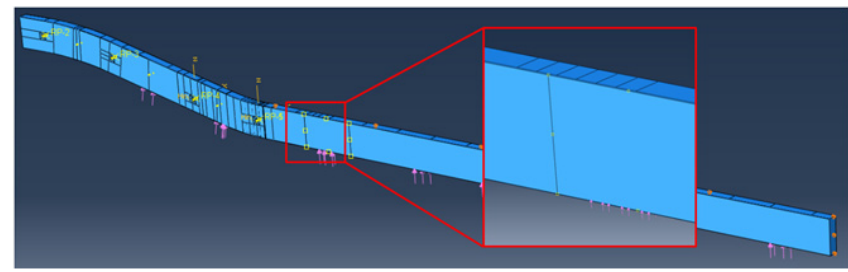

Fig. 28. Fine discretization of spar model at the rupture area.

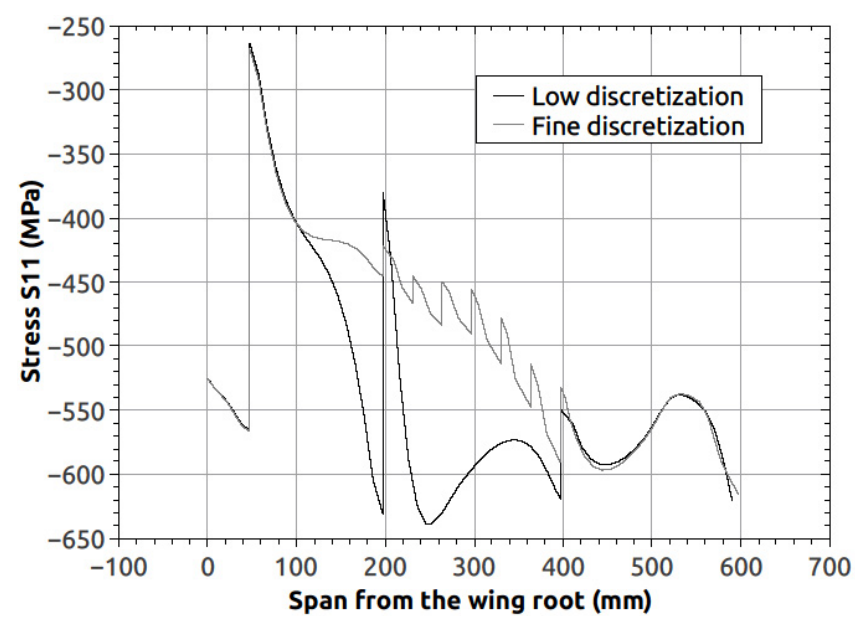

Fig. 29. Discretization influence on the fiber axis stress (noted S11) in the unidirectional upper flange.

and Aéro Composites Saintonges (ACS) and, the research institute PPRIME.

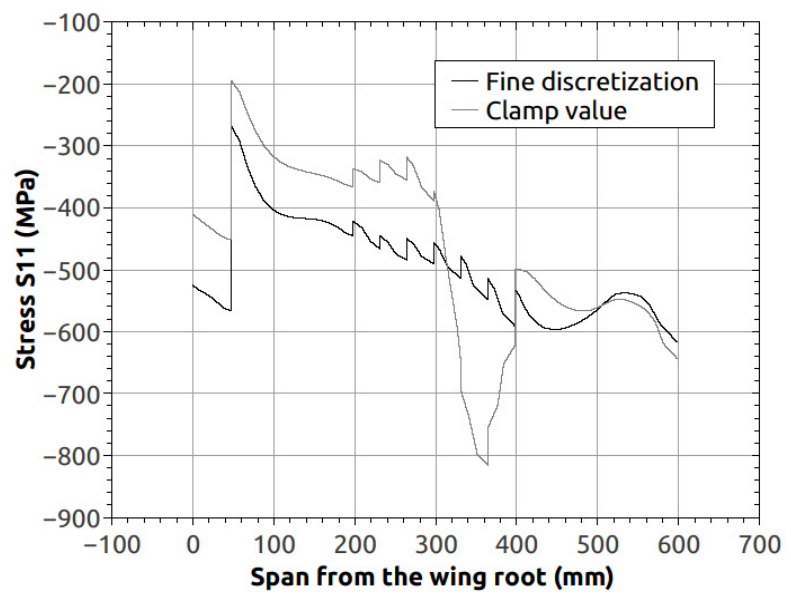

Fig. 30. Clamp value influence on the S11 stress in the unidirectional upper flange.

\section{References}

[1] G. Lubineau, P. Ladevèze, Construction of a micromechanics-based intralaminar mesomodel, and illustrations in ABAQUS/Standard, Comput. Mater. Sci. 43 (2008) 137-145

[2] F. Hélénon, M.R. Wisnom, S.R. Hallett, R.S. Trask, Numerical investigation into failure of laminated composite T-piece specimens under tensile loading, Composites: Part A 43 (2012) 1017-1027

[3] J. Reinoso, A. Blázquez, A. Estefani, F. París, J. Cañas, E. Arévalo, F. Cruz, Experimental and three-dimensional global-local finite element analysis of a composite component including degradation process at the interfaces, Composites: Part B 43 (2012) 1929-1942 
[4] A. Thionnet, J. Renard, Modelling unilateral damage effect in strongly anisotropic materials by the introduction of the loading mode in damage mechanics, Int. J. Fatigue 24 (2002) 147-154

[5] J.P. Berro Ramirez, D. Halm, J.C. Grandidier, Simulation de la rupture de structures composites par une approche à directions fixes de l'endommagement. Proceedings of Journées Nationales des Composites, JNC16, 2012

[6] F. Laurin, N. Carrère, J.-F. Maire, A multiscale progressive failure approach for composite laminates based on thermodynamical viscoelastic and damage models, Composites: Part A 38 (2007) 198-209

[7] P. Ladevèze, O. Allix, L. Gornet, D. Lévêque, L. Perret, A computational damage mechanics approach for laminates: identification and comparison with experimental results, Elsevier Science, 1998

[8] B. Gentilleau, Modélisation et validation expérimentale du comportement thermomécanique de multicouches polymère-composite bobiné-application au stockage d'hydrogène hyperbare, Ph.D. thesis, ENSMA, 2012

[9] Certification Specification of Very Light Aeroplane (CS VLA), European Aviation Safety Agency (EASA)

[10] Acceptable Means of Compliance 572, 613 and 619, CS VLA

[11] N. Revest, Comportement en fatigue de pièces épaisses en matériaux composites, Thèse, École Nationale Supérieure des Mines de Paris, 2011

[12] C. Bois, M. Colt, H. Wargnier, J.C. Wahl, Étude du transfert de charge dans les assemblages composites hybrides boulonnés et collés, Université de Bordeaux, Politechnica University of Bucharest, Comptes Rendus des JNC, 17
[13] F.J. Guild, D. Walton, R.D. Admas, D. Short, The application of acoustic emission to fibre-reinforced composite materials, Composites, July 1976, 173-179

[14] M. Giordano, A. Calabro, C. Esposito, A. D'Amore, L. Nicolais, An acoustic emission characterization of the failure modes in polymer-composite materials, Compos. Sci. Technol. 58 (1998) 1923-1928

[15] J.J. Scholey, P.D. Wilcox, M.R. Wisnom, M.I. Friswell, Quantitative experimental measurements of matrix cracking and delamination using acoustic emission, Composites Part A 41 (2010) 612-23

[16] A. Caladro, C. Esposito, A. Lizza, A. D'Amore, L. Nicolaist, An acoustic emission characterization of the failure modes in polymer - composite materials, Compos. Sci. Technol. 58 (1997) 1923-1928

[17] T. Uenoya, Acoustic emission and the fiber/matrix interface failure progress and strength in glass fiber/epoxy laminates, 10th ICCM, 1995, pp. 581-588

[18] N. Godin, S. Huguet, R. Gaertner, Influence of hydrolytic ageing on the acoustic emission signatures of damage mechanisms occurring during tensile tests on a polyester composite: Application of a Kohonen's map, Compos. Struct. 72 (2006) 79-85

[19] S. Momon, N. Godin, P. Reynaud, M. R'Mili, G. Fantozzi, Unsupervised and supervised classification of AE data collected during fatigue test on CMC at high temperature, Composites Part A 43 (2012) 254-260

[20] M. Bertin, Fatigue thermomécanique de multicouches polymère/composite, Ph.D. thesis, ENSMA, 2011 